\title{
Socially Efficient Stabilization Policies for Growth Cycles
}

\author{
Alexander V. Ryzhenkov \\ Faculty of Economics, Novosibirsk State University, Russia \\ Institute of Economics and Industrial Engineering, Siberian Branch of Russian Academy of Sciences, Russia
}

Copyright $(\mathcal{C} 2015$ by authors, all rights reserved. Authors agree that this article remains permanently open access under the terms of the Creative Commons Attribution License 4.0 International License

\begin{abstract}
This paper considers the Fanti and Manfredi Goodwinian two-dimensional model that stabilizes growth cycle by profit-sharing, although a long-term employment rate declines, whereas the stationary relative wage is not affected. For checking robustness of profit-sharing, flexible production capacity utilization is included. The Phillips Wolfstetter - Flaschel "capricious" investment function destroys stability of a non-trivial stationary state. Adding "neoclassically" balanced government taxes and expenditures results in attaining stable stationary state in a three-dimensional model. Yet stationary labor share and stationary employment ratio becomes lower than in the initial model. This paper revises the preceding equations. The first non-linear three-dimensional model implements proportional and derivative control over growth rate of profit. This rate depends on a gap between the indicated and current employment ratios and on growth rate of this ratio. The second four-dimensional model redefines this combined control applying excess income levy that equals subsidy. The previous models enable extreme condition tests for these Goodwinian and non-Goodwinian models. Parametric policy optimization shortens a transient to a deliberately high target employment ratio without lowering stationary relative wage against the Goodwinian models. The proposed policies enhance stability and efficiency of capital accumulation; they also provide stronger gains for workers' well-being.
\end{abstract}

Keywords Capital Accumulation, Class Struggle, Growth Cycle, Profit-sharing, Employment, Government Taxes and Expenditures, Production Capacity, Critique of Neoliberal Economic Policies, Closed-loop Control, Social Efficiency

\section{Introduction on Goodwin's Model (M-1) and its Extensions}

The Fanti and Manfredi [1] elaborated the famous Goodwin's version [2] of the Marxian growth cycle. The reader well remembers that the original Phillips nominal wage-change equation in [3] is non-linear where factors are the employment ratio, its rate of change and the rate of inflation. R.M. Goodwin [2] simplified this equation in his original model to a linear one for a rate of change of real wage dependent only on a single variable - the employment ratio.

Fanti and Manfredi [1] extended the simplified Phillips equation by a linear profit-sharing term that reflects the profit rate as a counter-cyclical factor in real wage-change equation. This term implies that ceteris paribus the higher relative profit compels capitalists to promote a growth rate of real wage that is detrimental for profit and profitability. Fanti and Manfredi [1] necessitates overt expression and resolution of this logical paradox expressing a certain objective tension in a subsequent research.

The other valuable achievement is a warning on possible detrimental effects of standard profit-sharing as demonstrated in [4]. The latter paper revises the equations for profit-sharing and bargained wage terms in the two substantially non-linear four-dimensional models of capital accumulation. The Fanti and Manfredi model built for closed economy for a specific accumulation rate $(k=1)$ when capitalists invest total profit in fixed capital is generalized for broader region of $k$; consequently, the original propositions are reconsidered.

An abrupt drop of the rate of accumulation can be destroyer for stabilization policy through standard profit-sharing. So models with endogenous rate of accumulation are required. Lordon [5] implicitly and Ryzhenkov [6-8] explicitly offered such Goodwinian models tested against data for the USA and Italy.

Still the models that hide an endogenous rate of capital accumulation under a veil of government taxes and expenditures represent a great interest for a deeper inquiry into the subject matter. Such models are developed at different corners of the world. The most well-known of them belongs to Wolfstetter [9], the other have been presented by Yoshida and Asada [10], later - by Flaschel [11].

The mystery in these works has been waiting for explanation: why government expenditures balanced by taxes in Goodwinian or semi-Goodwinian models reduce stationary gross and net labor shares in national income and can even lessen long-term employment ratio if standard profit-sharing is added? The voluminous literature on crowding-out effects, including [12], over-looks this fundamental problem and other important aspects of alternative stabilization policies.

The rest of this paper is organized for the reader's con- 
venience. Still reading will require serious efforts.

Each of this paper's sections states a number of propositions and corollaries. Appendix A contains their formal proofs except few omitted ones. Throughout this text a variable's time derivative is denoted by a dot, its growth rate - by a hat over the variable's sign. An ordinary differential equation is abbreviated as ODE.

Section 2 reviews briefly properties of a model of cyclical dynamics with profit sharing proposed in [1]. This model is abbreviated as M-2, whereas the Goodwin model - as M-1.

The M-2 intensive form is built into two-dimensional system of non-linear ODEs, local asymptotical stability of its non-trivial stationary state is exposed. Although the stationary relative wage remains the same as in M-1, the stationary employment ratio declines.

The Phillips [13] - Wolfstetter [9] - Flaschel [11] "capricious" investment function destroys stability of a non-trivial stationary state in a modified model M-3. Explosive investment behavior and breakdown (Zusammenbruch) because of dominant positive feedback loops mean that standard profit-sharing becomes a failed fix.

Section 3 steps back at first and removes the investment functions and, secondly, explores how balanced taxes and expenditures narrow workers profit-sharing in an attempt to enforce stability of capital accumulation in a new model M-4 that extends M-2. Here balanced government taxes and expenditures taken from [9] complement standard profit-sharing. Unfortunately not only the stationary employment ratio declines, the stationary relative wage also shrinks in relation to $\mathrm{M}-1$.

With a sufficiently strong profit-sharing not only 'neoclassical' but also 'Keynesian' policy stabilizes a non-trivial stationary state in M-4. The difference between both is connected in the first place to a multiplier - negative in the former and positive in the latter - at a gap between stationary and current employment ratios in an equation for a variable tax rate. It is proved, that at a critical positive magnitude of this parameter a simple Andronov - Hopf bifurcation happens and a closed orbit is generated in the phase space with a longer period than a period of conservative closed orbits in M-1.

The same "capricious" investment function worsens the systemic risk and complicates the problem of stabilization again in extended M-4 abridged as M-5. It is demonstrated that for a sufficiently strong "neoclassical" policy the asymptotical stability of a non-trivial stationary state is maintained. A possibility of singularity in this model because of a specific magnitude of the same control parameter is found out. These uncovered properties heavily restrict opportunities of the "neoclassical" stabilization policy and practically exclude a successful "Keynesian" stabilization policy in M-5.

Retaining the Marx irony in relation to mainstream political economy it is time for thinking unthinkable infringement of the "eternal" and so to say "sacred" law of supply and demand. It can happen as Marx insisted if employed and unemployed organize a regular co-operation between themselves in order to destroy or to weaken the ruinous effects of this natural law of capitalistic production on working class.

You can't buck the market, Margaret Thatcher, then Prime Minister, told the House of Commons in 1988. The next two sections fight back this neoliberal thesis and the "sacred" law of supply and demand. The author suggests how to modify its action in working class' and whole society's interests by forcible means and State interference that surpasses narrow bounds of neoliberal policies - either "neoclassical" or "Keynesian".

Section 4 offers a modernized model R-1 with a reinforced employment-centered stabilization policy. For testing robustness of profit-sharing, flexible production capacity utilization is included in R-1 similar to M-3. ${ }^{1}$

The modernized model upgrades profit-sharing applying a combination of proportional and derivative control over a growth rate of profit together with employment targeting. In result, a synthetic employment-rate-wage-change relationship is non-linear. Now besides a current employment ratio and its rate of change, factors determining a rate of change of real wage include a target employment ratio, a growth rate of output per worker and a rate of surplus value.

"Parasitic" (in the terminology of [9]) government taxes and expenditures are not required in R-1 at all for a more efficient stabilization than in the preceding models. ${ }^{2} \mathrm{~A}$ stationary relative wage is the same as in M-1 (higher than in M-4), stationary employment ratio is deliberately higher than in $\mathrm{M}-1$, whereas stationary relative excess income levy equals zero.

Section 5 presents X-1 as a shortening of R-1 after removing the investment functions. This model confirms the main results on reinforced stabilization policy. The next modification R-2 implements the employment-centered stabilization policy through excess income levy that equals subsidy. Whereas an intensive form of X-1 is a system of two ODEs for relative wage and employment ratio, an intensive form of R-2 augments the former by two non-linear ODEs by transforming two parameters of the linear Phillips equation into variables thus an intensive form of this model consists of four nonlinear ODEs. An analysis finds out that the latter system is decomposable and has an asymptotically stationary state similar to the previous one of lower dimensionality in X-1.

Section 6 sums up the main results. Even Maxwell's thermodynamics demon would be happy with such accomplishments of the proposed feedback and feed-forward control that maintains capital accumulation, relative wage and employment. A booklover may recall Shakespeare's "Taming of the Shrew".

This work develops results $[16,17]$ deepening their elucidation, mostly releasing theoretical statements from game

\footnotetext{
${ }^{1}$ Users of dynamics in many scientific disciplines, including economics, attach great importance to robust dynamical properties: a feature of a dynamical system is robust if it persists under all sufficiently small perturbations of the system. The ultimate robust property is that of structural stability [14].

${ }^{2}$ This section challenges, in particular, the neoliberal view in [9] that "[polemically] speaking, the "state" ... is ... a "macroparasite" who preys upon the public without providing direct benefits to any subgroup." Learning from the history [15], we may see the task of State actions in providing social benefits greater (and no less) than social costs especially when 'invisible hand' fumbles.
} 
theory terms. The study applies mathematical theory of nonlinear differential equations from [14, 18]. Multiple simulation experiments with a soft-ware package Vensim have been carried out based on the models presented in the next sections.

Causal loop diagrams maintain the theoretical propositions and visualize them applying the system dynamics instruments exposed in [19].

G20 leaders at the Antalya Summit have agreed that reducing inequality, creating quality jobs and ensuring inclusion are essential to promote robust growth [20]. Still they "fell short of the action needed" [21]. This paper applies a powerful system dynamics method for elaborating socially efficient stabilization policies, particularly intended to alleviate next global recession.

\section{Two Dynamic Models with Prof- it-sharing (M-2 and M-3)}

\subsection{The M-2 Extensive Form}

I shortly review a simplified model presented in [1] and critically analyzed in [4].

Laborers are advancing capitalists as they receive wage after a particular circuit of capital is finished. Having abstracted from the public sector and foreign economic relations, M-2 consists of the following equations:

$$
\begin{gathered}
P=K m \\
a=P / L ; \\
u=w / a, \\
0<u<1 ; \\
\hat{a}=h>0, \\
m=\text { const }<1 ; \\
v=L / N, \\
0<v<1 ; \\
N=N_{0} e^{n t}, \\
n=\text { const } \geq 0, N_{0}>0 ; \\
\hat{w}=-g+r v+e(1-u) m, \\
g>0, r>0,0<e<k h / d ; \\
P=C+\dot{K}=w L+(1-k) S+\dot{K} ; \\
\dot{K}=k S=k(1-u) P, \\
d / m<k \leq 1 .
\end{gathered}
$$

Equation (1) specifies a technical-economic relationship between fixed capital $K$ and net output $P$. Output-capital ratio is denoted by $m$. Equation (2) expresses output per worker $a$ as a ratio of net output $P$ to employment $L$. Equation (3) describes relative wage as wage share in net output $u$. Equation (4) assumes a constant exogenous growth rate of output per worker $a$ that equals to a growth rate of capital intensity $K / L$, whereas output-capital ratio $m$ remains constant according to equation (5).

Equation (6) defines employment ratio $v$ as a result of the sale of the labor power. According to (7), the growth rate of labor force $N$ is equal to constant $n$. Equation (8) links the growth rate of real unit wage $w$ with employment ratio $v$ and profit rate $(1-u) m$.

The use of current profit reflects absence of information lags for laborers regarding the actual relative wage. In other words, capitalists and workers receive information on relative wage in real time.

A growth rate of wage is the sum of bargained $\hat{w}^{m}$ and profit sharing $\hat{w}^{b}$ terms

$$
\hat{w}=\hat{w}^{m}+\hat{w}^{b},
$$

where the first is determined by employment ratio $v$ as in a linear Phillips equation

$$
\hat{w}^{m}=-g+r v
$$

and the second - by profit rate

$$
\hat{w}^{b}=e(1-u) m,
$$

here $e>0$ is a profit sharing index.

Balance equation (9) shows the end use of net output $P$, where $C$ is a private consumption, $\dot{K}$ is net fixed capital formation defined in the equation (10). Investment delays as well as discrepancies between orders and inventories are not taken into explicit account.

Surplus product $S$ that equals total profit $M$ can be not only invested, but also be used to cover personal expenses of the bourgeoisie. Consequently, rate of accumulation $k$, or share of investments in surplus product, is such that $d / m<k \leq 1$. The left boundary is set to avoid a non-positive stationary relative wage.

The presence of $d / m$ as a lower boundary for rate of accumulation $k$ is a drawback of both $\mathrm{M}-1$ and $\mathrm{M}-2$, since in reality relative wage remains positive even when $d / m \geq k$. This means they do not pass this particular extreme condition test. Models in [6-7] contain endogenous capital-output ratio and endogenous rate of accumulation in the absence of the specified lower bound as a real necessity. Long-term decline in this ratio mitigates the tendency of profit rate to fall in the USA, Italy and other industrialized countries.

Figure 1 and Table 1 present a causal loop structure of M-2. The negative feedback loop B2 reflects the positive influence of relative profit $(1-u)$ on growth rate of profit-sharing wage term that is detrimental for profit rate. The improved profitability promotes increases of employment ratio that facilitate higher bargained wage term to the detriment of profit rate in negative feedback loop B1.

Fanti and Manfredi [1] does not explain how capitalists are compelled to increase wage along with increases in relative profit and profitability. This issue will be further discussed in subsection 4.1. 


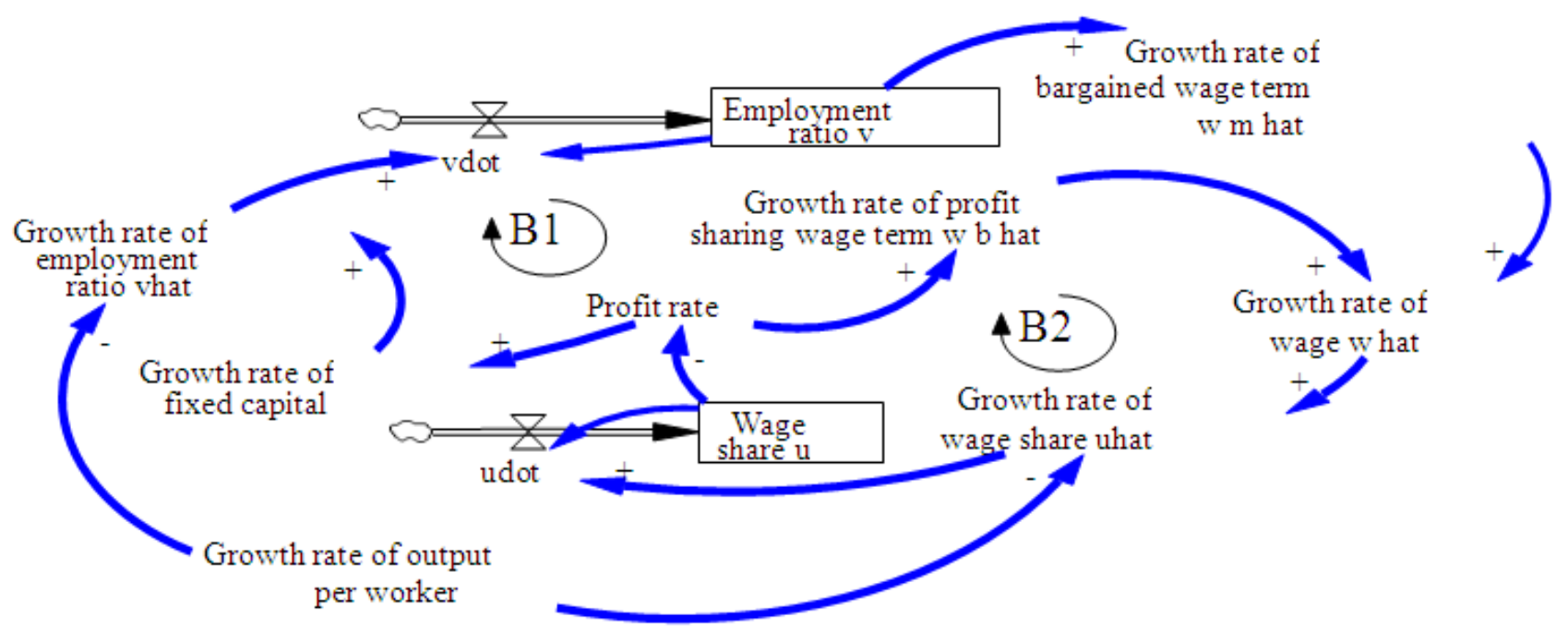

Figure 1. A causal structure of M-2 without information delay in relative wage $u$

Table 1. Two main negative feedback loops in M-2

\begin{tabular}{|c|c|}
\hline Loop B1 of length 9 & Loop B2 of length 5 \\
\hline $\begin{array}{c}\text { Wage share } u \longrightarrow \\
\text { Profit rate } \\
\text { GR fixed capital } \\
\text { GR employment ratio } \\
\text { Net change of } v \\
\text { Employment ratio } v \\
\text { GR bargained wage term } \\
\text { GR wage } \\
\text { GR wage share } \\
\text { Net change of } u\end{array}$ & $\begin{array}{c}\text { Wage share } u \stackrel{-}{\longrightarrow} \\
\text { Profit rate } \\
\text { GR profit sharing wage term } \\
\text { GR wage } \\
\text { GR wage share } \\
\text { Net change of } u\end{array}$ \\
\hline
\end{tabular}

Note. Only a negative first partial derivative is explicitly shown as an arrow. All other first partial derivatives are positive. GR is for "Growth rate of".

Negative feedback loop B1 is inherited from M-1, negative feedback loop B2 is due to the profit-sharing rule. Besides these, M-2 includes two $1^{\text {st }}$ order feedback loops for relative wage $u$ and employment ratio $v$ with alternating polarity. 


\subsection{The M-2 Intensive Form and Properties of Its Sta- tionary State}

According to [1], an intensive form of deterministic M-2 without information delays consists of two non-linear ODEs. Here is this system in a generalized form for $d / m<k \leq 1$ in relation to the original form (for $k=1$ ):

$$
\begin{gathered}
\dot{u}=[-g+r v+e(1-u) m-h] u, \\
\dot{v}=[k(1-u) m-d] v .
\end{gathered}
$$

A positive stationary state of the system (14)-(15) is defined as

$$
E_{a}=\left(u_{a}, v_{a}\right)
$$

where $u_{a}=u_{G}=1-\frac{d}{k m}, v_{a}=v_{G}-\frac{e d}{k r}<v_{G}=\frac{g+h}{r}$.

A stationary growth rate of output per worker and growth rate of wage equals $h$. A stationary growth rate of fixed capital and net output is $\hat{K}_{a}=\hat{P}_{a}=d=h+n$. A stationary rate of surplus value is $m_{a}{ }^{\prime}=m_{G}{ }^{\prime}=\frac{1-u_{a}}{u_{a}}$. A stationary profit rate is $\left(1-u_{a}\right) m_{a}=d / k, d \geq h$.

Let us pay also attention to a very important positive dependence of the stationary relative wage and employment ratio on the rate of accumulation: $\frac{\partial u_{a}}{\partial k}=\frac{d}{m k^{2}}>0$, $\frac{\partial v_{a}}{\partial k}=\frac{e d}{r k^{2}}>0$. As we see below (subsection 3.1) this property surprisingly explains effects of government taxes and expenditures on stationary relative wage and employment ratio in subsequent models.

Proposition 1 . The stationary state $E_{a}$ is (a) stable node or focus depending on parameters and therefore (b) hyperbolic.

The second panel of Figure 2 reflects a stable focus in M-2 replacing neutral center in $\mathrm{M}-1$ on the first panel.

M-2 establishes divide between long-term steady state growth and jobs creation that deserved careful consideration in [4]. One of the model main paradoxes resides in stabilization policy that governs economy to lower employment ratio in the long-term than before the policy onset. For the same common parameters, the stationary employment ratio is lower in M-2 than in M-1: $v_{a}<v_{G}$. The relative decline of stationary employment ratio after onset of the stabilization policy is $\frac{v_{a}-v_{G}}{v_{G}}=-\frac{e}{k} \frac{d}{g+h}$ in agreement with definition (16). This has other harmful consequences unnoticed in [1].

The magnitudes of parameters and of main variables are mostly taken from [1]. The initial year is denoted as 1958 for illustrative definiteness without a particular relation to a certain national economy.
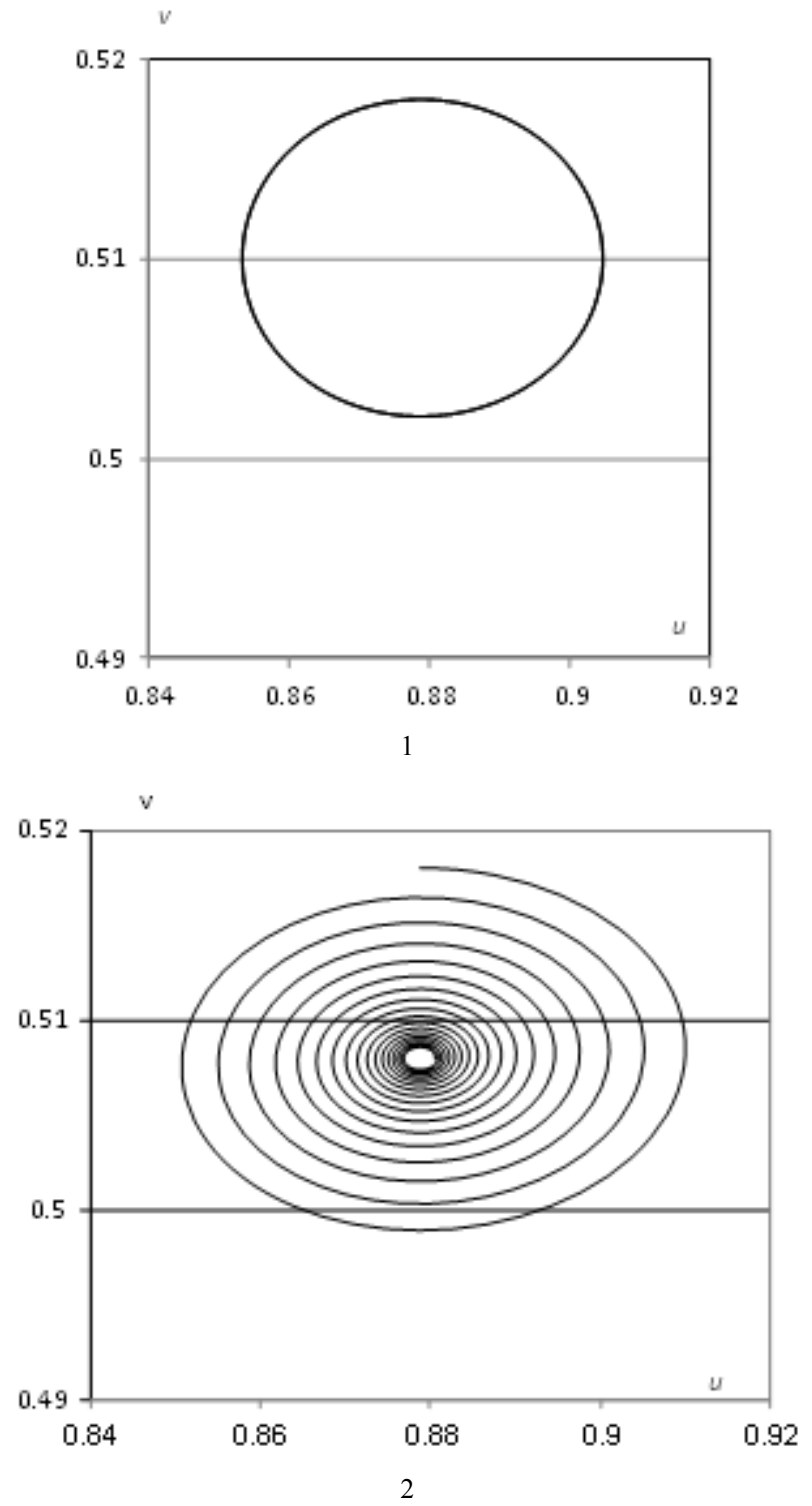

Figure 2. A neutral center in M-1 (panel 1) and stable focus in M-2 (panel 2), clock-wise, 1958-2158: initial conditions: $u_{0}=0.8788, v_{0}=0.5180$; common parameters: $g=1, h=0.02, k=1, m=0.33, n=0.02, r=2$, additionally $e=0.1$ in M-2, stationary: $u_{a}=u_{G} \approx 0.8788$ and $v_{a} \approx 0.5080<v_{G}=$ 0.51 , periods: $T_{M-2}=11.57>T_{M-1}=11.55$ years

The profit-sharing rule does not alter the stationary relative wage $u_{G}$ inherited from M-1. Other stationary magnitudes (ratios and growth rates) also coincide. The long run distribution is yet left inalterable only in relative terms! As the proposed stabilization policy reduces long run employment ratio $v$ of steady growing labor force $N$, the employment $L$, net output $P$, surplus value $S / a$, total wage $w L$, consumption per head $w v$ and profit $M$ are, as a rule, lower in M-2 than they would be in M-1. This policy worsens reproduction and use of economic (first of all - labor) potential in the long-term and typically even in the middle term. In particular, the higher profit sharing index $e$, the lower are the long-term and usually even middle term output and 
employment. ${ }^{3}$ These "side-effects" of standard profit-sharing are tackled with a help of the mathematical control theory.

\section{Proportional Control in $M-2$}

An equivalent for (14) takes the form of combined proportional control over the net change of relative wage defined by deviations of employment ratio and profit rate from their stationary magnitudes

$$
\dot{u}=r\left(v-v_{a}\right) u+e\left[(1-u) m-\frac{d}{k}\right] u .
$$

An equivalent for (15) reflects proportional control over the net change of employment ratio

$$
\begin{aligned}
\dot{v} & =k\left[(1-u) m-\frac{d}{k}\right] v \\
& =k m\left(u_{G}-u\right) v .
\end{aligned}
$$

The equations for two terms of the growth rate of wage can be equivalently presented as manifestation of combined proportional control in the respective elementary forms

$$
\begin{gathered}
\hat{w}^{m}=r\left(v-v_{a}\right)+h-e \frac{d}{k}, \\
\hat{w}^{b}=e\left[(1-u) m-\frac{d}{k}\right]+e \frac{d}{k} .
\end{gathered}
$$

This proportional control is embryonic in [1] as in [5] since there is no conscious targeting of employment ratio. This is because of predominance of the dogma of natural rate of unemployment taken uncritically from the mainstream economics. More developed forms of social control are a characteristic of new set of models R-1, X-1 and R-2 (Sections 4 and 5) beyond the Lordon, Fanti and Manfredi type.

\subsection{Explosive Investment Behavior and Breakdown in an Extended Model (M-3)}

An abrupt drop of the rate of accumulation can be destroyer for stabilization policy that relies on standard profit-sharing. So models with investment functions are required for deeper inquiries. Papers [5-8] offered such Goodwinian models.

A particularly challenging case of investment function is proposed in $[9,11,13]$ for explaining how a degree of production capacity utilization is determined. In particular, [9] stipulated that firms consider a certain amount of excess capacity as desirable, since it allows them to cash in on demand fluctuations.

Instead of the equation (1) we have now

$$
P=m K x,
$$

where new variable $x$ is a rate of production capacity utilization. Profit rate is now $(1-u) m x$.

Wolfstetter [9] added two further assumptions: 1) firms are uncertain concerning the deviation of the short-run $(\gamma)$ from the long-run rate of growth in aggregate demand $(d)$, i.e. the expected value of $(\gamma-d)$ is zero; 2$)$ a simple exponential error adjustment process with finite speed of response, $\varepsilon$. Since the assumed existence of a steady state solution $d$ equals the natural rate of economic growth, $\gamma_{n}=h+n$, the following equation defines the investment function:

$$
\begin{gathered}
\dot{\hat{K}}=\varepsilon\left[d-\hat{K}+\left(x / x_{a}-1\right) \theta\right]= \\
\varepsilon(d-\hat{K}+x-1)=k m[\dot{x}(1-u)-x \dot{u}],
\end{gathered}
$$

where growth rate of fixed capital is $\hat{K}=k m x(1-u)$, conversion factor $\theta=1\left[\frac{1}{\text { year }}\right]$ serves conformity of units of measurement, $\varepsilon$ is the adjustment parameter, $x$ and $x_{a}=1$ denote the actual and the desired (exogenously given stationary) degree of production capacity utilization. Both $\theta$ and $x_{a}$ are omitted in the final form of (22) and in equations below for brevity.

It follows from (22) that

$$
\begin{gathered}
\dot{x}=\left[\varepsilon(d-1+x-\hat{K})+\dot{u} \frac{\hat{K}}{1-u}\right] \frac{x}{\hat{K}}= \\
\varepsilon[d-1+x-k m x(1-u)] \frac{1}{k m(1-u)}+\frac{\dot{u} x}{1-u} .
\end{gathered}
$$

The latter equation is a generalization of a time derivative of production capacity utilization rate for the particular investment function [11] with $0<k \leq 1$.

Now we have all the necessary interconnected elements for a death spiral.

\section{The Intensive Form and Instability of Stationary State}

Besides (23) the M-3 intensive form contains the following two non-linear ODEs

$$
\begin{aligned}
& \dot{u}=[-g+r v+e m x(1-u)-h] u, \\
& \dot{v}=[k m x(1-u)-h-n+\hat{x}] v
\end{aligned}
$$

A positive stationary state of this system is defined as

$$
S_{a}=\left(u_{a}, v_{a}, x_{a}\right),
$$

where $x_{a}=1$ and as before $u_{a}=u_{G}=1-\frac{d}{k m}, v_{a}=v_{G}-\frac{e d}{k r}<v_{G}$. Here a stationary growth rate of output per worker and growth rate of wage equals $h$. A stationary growth rate of fixed capital and net output is $\hat{K}_{a}=\hat{P}_{a}=d=h+n, d \geq h$. A stationary rate of surplus value is $m_{a}{ }^{\prime}=\left(1-u_{a}\right) / u_{a}$. A stationary profit rate is $\left(1-u_{a}\right) m=d / k$.

Proposition 2. Stationary state $S_{a}(26)$ is (a) unstable and (b) hyperbolic.

\footnotetext{
${ }^{3}$ For a particular closed orbit in M-1, the average magnitudes of relative wage and employment ratio are practically the same as their stationary counterparts. A similar correspondence is weaker for a stable focus or node in $\mathrm{M}-2$.
} 
Co r o l l a ry. If the investment function is added to M-1 (for $e=0$ ), Proposition 2 remains true.

Independently of how strong is profit-sharing measured by index $e$, it is not able to stabilize capital accumulation with the chosen investment function.

Like subprime lenders in the recent financial bubble, investors in productive assets in my story "ate their own cooking, and got poisoned" collectively if not individually. In this worst-case scenario, the economy is undermined by rational irrationality. ${ }^{4}$

In the first instance this is due to the positive dependence of $\dot{x}$ on $x$ and, secondly, because of a positive dependence of $\dot{v}$ on $v$. This model can even be with co-operation between $u, v, x$, containing no competition for jobs, and possessing only 'intra-specific' competition in $u$. In particular, at the stationary state $\frac{\partial \dot{v}}{\partial u}>0$ as a rule, since typically $\varepsilon>d+e m u_{a}$ thanks to capitalists" "animal spirits". Strictly speaking this is not Goodwinian (predator-prey) model. In particular, for $e=0$ as in M-1 stationary state (26) is utterly unstable too.

Panel 1 of Figure 3 shows uncontrolled boom. The following values of parameters are used: $e=0.1, g=1, h=0.02$, $k=1, m=0.33, n=0.02, r=2, \varepsilon=0.8$. Within a few months profit rate (right scale), employment (left scale) and the rate of production capacity utilization $(x)$ grow uncontrollably, ceiling is reached for full employment: if for $t_{0}=1958 v_{0}=v_{a}$ $=0.508, u_{0}=u_{a}=0.879, x_{0}=x_{a}+0.0001=1.0001$, then $v \approx$ 0.99 for $t=1958.34$.

Panel 2 of Figure 3 illustrates a collapse for the same parameters' magnitudes. Within a few months the almost sheer profitability drop (right scale) has been accompanied by the similar decline in per capita consumption of workers (left scale) and capacity utilization $x$. A minimum level of average worker's consumption set equal to $40 \%$ of the baseline $w_{0} v_{0}$ for $x_{0}=x_{a}-0.0001=0.9999$, as well as for previous $v_{0}$ and $u_{0}$.

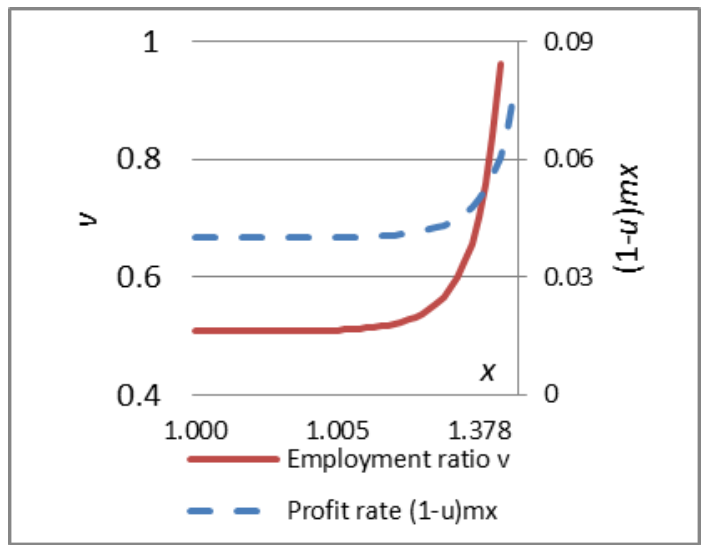

1

\footnotetext{
${ }^{4}$ This metaphor and the term rational irrationality are taken from [22]. Rational irrationality - objectively determined behavior that, on the individual level, is perfectly reasonable but that, when aggregated in the marketplace, produces calamity [23].
}

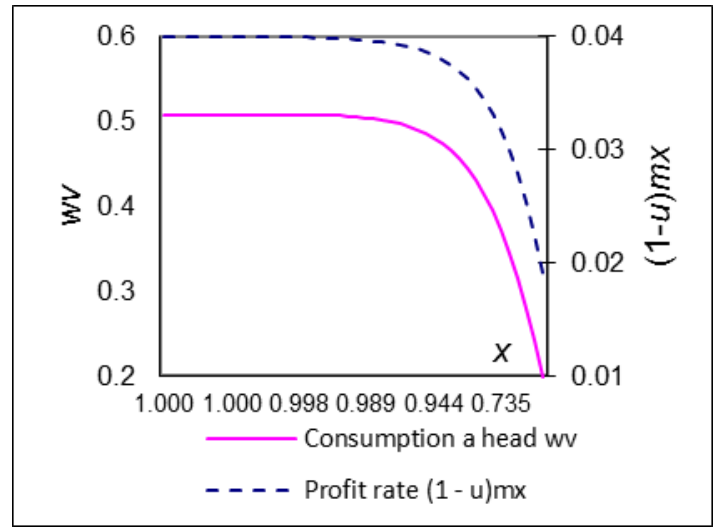

2

Figure 3. Aggravation modes in M-3, 1958-1958.35. Panel 1 - uncontrolled strength, ceiling - full employment $v \approx 0.99$ in 1958.34 ; panel $2-$ uncontrolled weakness, floor - subsistence consumption a head

The simulation results would be qualitatively the same if $\varepsilon$ $=0.2>d+e m u_{a}=0.043$ as in [11] were used.

We see that profit-sharing under the stipulated investment behavior becomes a fix that fails due to the dominant positive feedback loops (Figure 4) that propel the model economy to death. The nightmare of complete breakdown (Zusammenbruch) is awakened.

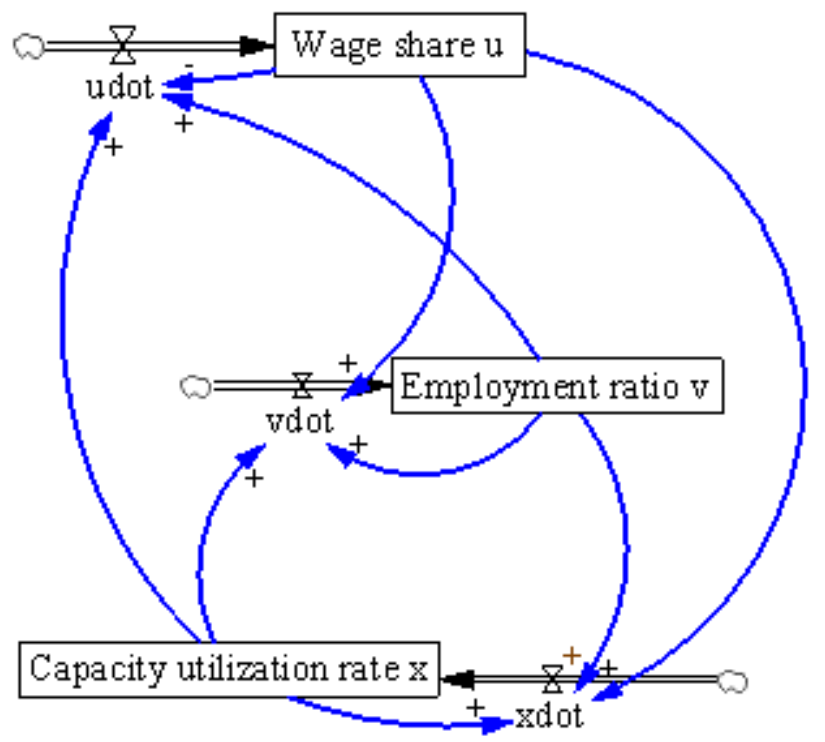

Figure 4. A condensed causal loop structure of M-3 with polarity typical for a vicinity of the stationary state; total number of feedback loops -8 , among them: $1^{\text {st }}$ order $-3(1$ - negative, 2 -positive $), 2^{\text {nd }}$ order -3 positive, $3^{\text {rd }}$ order -2 positive

Still we should not succumb to a vision of this dangerous opportunity. Questions for the system dynamics specialists suggest themselves. First, how can we convert the dominant positive feedback loops into negative? More technically, second, how do we turn two positive partial derivatives $\frac{\partial \dot{v}}{\partial v}$ and $\frac{\partial \dot{x}}{\partial x}$ for a stationary state into negative for curing the self-reinforcing explosive processes? Third, what will be a "price" of this conversion? 


\section{Balanced Taxes and Expenditures Narrowing Workers' Profit-sharing}

\subsection{A Model of Growth Cycle with a Cyclically Non-neutral Government Sector (M-4)}

Cassidy [22] observes disproving an ode to the invisible hand: "...what usually enables modern economies to "right themselves" is prompt government action".

To discuss the effects of fiscal policies, Wolfstetter [9] introduced a public sector into the model. His definition of a tax base is flawed due to confusion between productive and fictitious capital (debt in form of bonds). The same drawback is the characteristic of the Flaschel [11] update of the Wolfstetter model. ${ }^{5}$ It is possible still to extract a valuable element of their considerations for a balanced budget when this confusion does not matter. This refinement leads to a technically more complicated model than proposed in $[9,11]$.

Let $T$ and $G$ denote government taxes and expenditures, respectively. They are quantitatively the same by my assumption. Equation (27) describes a government policy rule that implies constant proportion $\delta \geq 0$ of government spending and taxing in national income for the steady state with employment ratio $v^{*}$

$$
T=\delta_{1} P=G=\delta P+\mu\left(v^{*}-v\right) P,
$$

where rather fuzzy still quite plausible bounds may be set as $0.5 \geq \delta_{1} \geq 0,0.5 \geq \delta \geq 0,|\mu| \leq 3$. Non-vague bounds for specific values of parameters $\delta$ and $\mu$ can be determined only with a help of computer simulations. The case $\delta_{1} \equiv 0$ is implicit for M-1, M-2 and M-3.

Equation (27) implies $\delta_{1}=G / P=T / P=\delta+\mu\left(v^{*}-v\right)$. Notice that $\dot{\delta}_{1}=-\mu \dot{v}$.

A 'Keynesian' policy, according to Wolfstetter [9], would attempt to counteract the cycle by choosing $\mu>0$, whereas a 'neoclassical' policy would reduce government expenditures in the slump and is thus characterized by $\mu<0$.

We will consider government stabilization policy together with profit-sharing still without explicit rate of capacity utilization in modified two-dimensional model M-4.

National income is the sum of gross incomes of workers and capitalists:

$$
w L+M=P .
$$

After government taxes and expenditures are added consumption of workers and capitalists is presented as

$$
C=C_{w}+C_{c},
$$

where

$$
\begin{gathered}
C_{w}=w\left(1-\delta_{1}\right) L, \\
C_{c}=(1-k) M\left(1-\delta_{1}\right)=(1-k)\left(1-\delta_{1}\right)(1-u) P .
\end{gathered}
$$

\footnotetext{
${ }^{5}$ A corrected definition of a tax base without noticing its incongruity in [9] was proposed in [10] for a similar framework. This definition was not taken into account in [11]. Still the refinement in [10] is not sufficient since practical and logical problems in treating even balanced State taxes and expenditures remain unresolved as the beginning of Section 5 explains.
}

Turn attention to budget constraints. Start with the workers' budget constraint

$$
P u\left(1-\delta_{1}\right)-C_{w}=0,
$$

$u=w / a$ is the wage share in national income before taxes on wages and profits are paid.

Proceed to the capitalists' budget constraint

$$
P(1-u)\left(1-\delta_{1}\right)-\dot{K}-C_{c}=0,
$$

where investment are equal to net fixed capital formation $\dot{K}=k M\left(1-\delta_{1}\right), 0<d / m<k(1-\delta)=$ const $\leq 1, \hat{K}=$ $k\left(1-\delta_{1}\right)(1-u) m$. The growth rate of fixed capital is a modification of the similar one in subsection 2.1.

The previous literature with an implicit rate of capital accumulation overlooked the effect of tax rate $\delta_{1}$ on this key variable. Now the rate of capital accumulation can be defined as $c=k\left(1-\delta_{1}\right)<k$ for $\delta_{1}>0$ assumed here and below. This lowering affects strongly the main characteristics of macroeconomic dynamics.

Product market equilibrium requires

$$
\begin{gathered}
P=C+\dot{K}+G= \\
w\left(1-\delta_{1}\right) L+(1-k) M\left(1-\delta_{1}\right)+\dot{K}+G .
\end{gathered}
$$

After rearranging and substituting net capital formation is obeying the material balance

$$
\begin{gathered}
\dot{K}=P(1-\delta)-\left[w\left(1-\delta_{1}\right) L+(1-k) M\left(1-\delta_{1}\right)\right]- \\
-\mu\left(v^{*}-v\right) P .
\end{gathered}
$$

Figure 5 displays a causal-loop structure of the extended model. The only new feedback loop reflected in Table 2 can be stabilizing (B3) or destabilizing (R1) depending on $\operatorname{sgn}(\mu)$. The other feedback loops are inherited from M-2.

Table 2. A new main first-order feedback loop in M-4

\begin{tabular}{|c|}
\hline Loop R1 $(\mu>0)$ or B3 $(\mu<0)$ of length 4 \\
\hline Growth rate of employment ratio \\
Net change of $v$ \\
Employment ratio $v \stackrel{-}{\longrightarrow}$ for $\mu>0$ \\
or $\stackrel{+}{\longrightarrow}$ for $\mu<0$ \\
Tax rate $\delta_{1} \stackrel{-}{\longrightarrow}$ Growth rate of fixed capital
\end{tabular}

The intensive form of M-4 can be easily derived. We assume gross profit-sharing as in M-2 since production and primary distribution of national income lie at very heart of workers-capitalists economic relations.

The first ODE for the relative wage is given by (14). The second ODE is for the employment ratio

$$
\begin{gathered}
\dot{v}=(\hat{K}-d) v= \\
{\left[k\left(1-\delta_{1}\right)(1-u) m-d\right] v=} \\
\left\{k\left[1-\delta-\mu\left(v^{*}-v\right)\right](1-u) m-d\right\} v,
\end{gathered}
$$

where $1>\delta>0,0<\delta_{1}=\delta+\mu\left(v^{*}-v\right)<1$. 


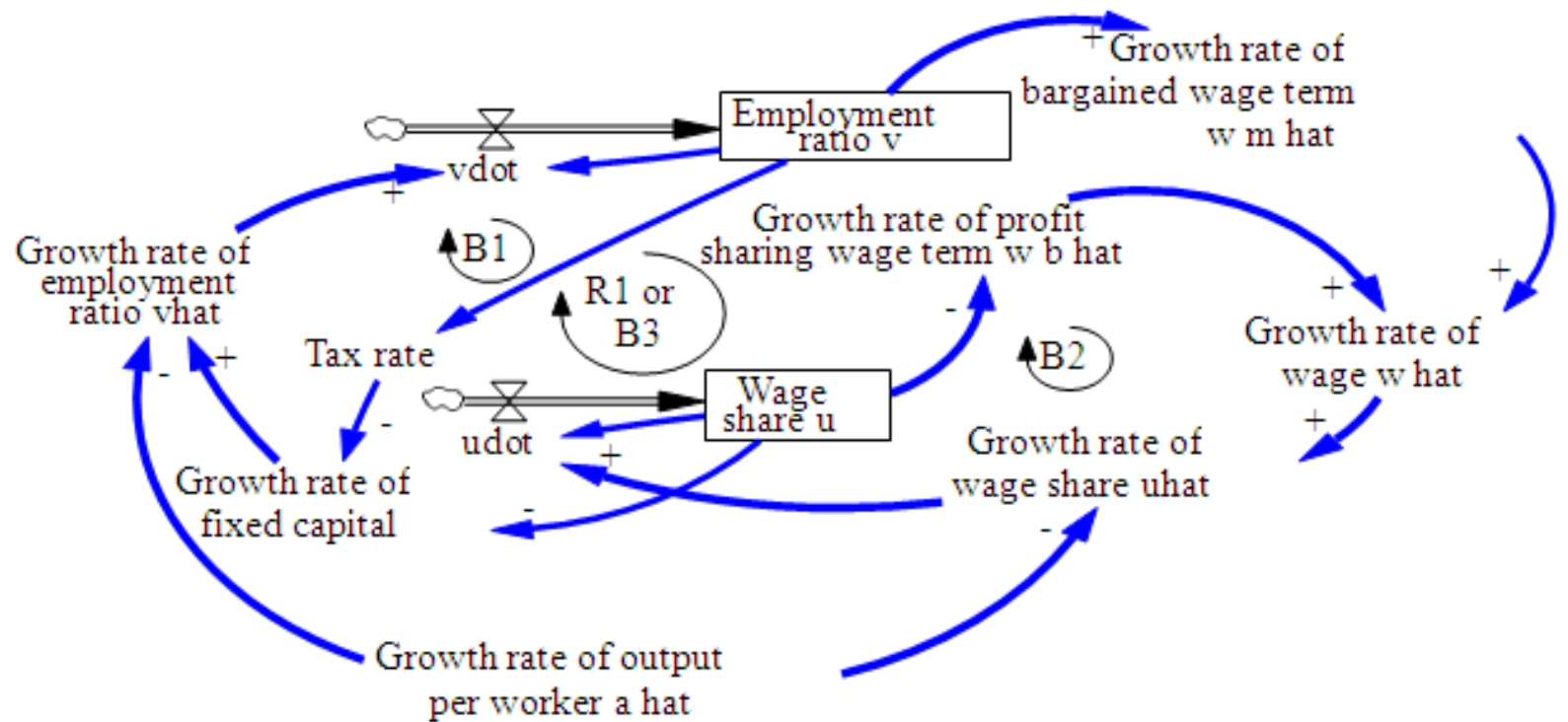

Figure 5. A causal structure of M-4 (after factoring out profit rate for brevity)

The first time derivative of the true rate of capital accumulation is: $\dot{c}=-k \dot{\delta}_{1}=k \mu \dot{v}$. So this is directly connected with the time derivative of the employment ratio if $\mu>0$. For $\mu<0$, the higher is $\dot{v}$ the lower is $\dot{c}$. Therefore the following interpretation suggests itself: the 'Keynesian' policy with $\mu>0$ is pro-cyclical with respect to the rate of capital accumulation whereas the 'neoclassical' policy with $\mu<0$ is counter-cyclical. ${ }^{6}$

A positive stationary state of the system (14)-(34) is defined as

$$
E_{b}=\left(u_{b}, v_{b}\right),
$$

where $0<u_{b}=1-\frac{d}{k(1-\delta) m}<u_{a}=u_{G}<1,0<v_{b}=$ $v_{G}-\frac{e d}{k(1-\delta) r}<v_{a}<v_{G}<1$. A stationary rate of surplus value before taxes is $m_{b}{ }^{\prime}=\frac{1-u_{b}}{u_{b}}>m_{a}{ }^{\prime}$. Stationary rates of profit before and after taxes are $\left(1-u_{b}\right) m=\frac{d}{k(1-\delta)}>\left(1-u_{a}\right) m$ and $\frac{d}{k}=\left(1-u_{a}\right) m$, respectively. Stationary employment ratio $v_{b}$ substitutes $v^{*}$ in (34).

A stationary net relative wage is defined quite independently of profit-sharing index $e$ :

$$
u_{b n e t}=u_{b}(1-\delta)=1-\delta-\frac{d}{k m}=u_{G}-\delta<u_{a}=u_{G} .
$$

Basically expressions for $u_{b}$ and $u_{a}$ as well as for $v_{b}$ and $v_{a}$ are qualitatively the same because they use the same ex-

\footnotetext{
${ }^{6}$ An opposite (honestly, rather superfluous) interpretation disconnected from the rate of capital accumulation in a model (similar to Wolfstetter's model) was given in [10]: "Government's fiscal policy is counter-cyclical when $\mu>0$, while it is pro-cyclical when $\mu<0$." The authors of that paper did not discuss the effects of stabilization policies on a stationary rate of capital accumulation, stationary employment ratio and stationary relative wage.

A deeper analysis of [10] goes beyond a limited scope of my paper that does not emphasize effective demand and effects of the policy lag on macroeconomic stability that are in the focus of their research.
}

pression for stationary relative wage $1-\frac{d}{c_{b} m}$ and the same expression for stationary employment ratio $v_{G^{-}} \frac{e d}{c_{b} r}$. The discrepancy between $u_{a}$ and $u_{b}$ as well as between $v_{a}$ and $v_{b}$ are based on the difference in the stationary rate of capital accumulation: $\quad c_{a}=k$ in $\mathrm{M}-2$ and $c_{b}=k(1-\delta)$ in M-4.

Stationary relative wage $u_{b}$ and stationary employment ratio $v_{b}$ for $e>0$ are both lower than previous ones (respectively, $u_{a}$ and $v_{a}$ ) because the current stationary rate of capital accumulation $k(1-\delta)$ is lower than the previous one $k$. This explains the mystery stated in Introduction.

Restrictions on a stationary rate of accumulation seem stronger in M-4 than in M-2 and M-3: $1 \geq k>\frac{d}{m(1-\delta)}>0$. Still for a generalized stationary rate of capital accumulation $c_{b}$ they remain the same as before: $1 \geq c_{b}>\frac{d}{m}>0$. A failure to pass extreme condition test remains: the requirement $u_{b}>0$ is violated for $k \leq \frac{d}{(1-\delta) m}$ or $c_{b} \leq \frac{d}{m}$.

We would like to emphasize growing inequality in class distribution of net output in M-4 against M-2 as result of government taxes and expenditures. The stationary gross and net relative wage declines. There is also worsening of the long-term employment ratio. Consumption a head $w v\left(1-\delta_{1}\right)$ is also ceteris paribus lower in M-4 than in M-2.

For the system of the two ODEs (14) and (34), (37) defines the Jacobi matrix:

$$
J_{M-4}=\begin{array}{|c|c|}
\hline \hat{u}-e m u & r u \\
\hline-k m\left[1-\delta+\mu\left(v-v_{b}\right)\right] v & \hat{v}+k m \mu(1-u) v \\
\hline
\end{array}
$$

Contrary to M-3 and similar to M-2, M-4 belongs to Goodwin-type (predator-prey) models as $\frac{\partial \dot{v}}{\partial u}<0$ and $\frac{\partial \dot{u}}{\partial v}>0$. 


\subsection{A Local Stability Analysis}

The Jacobi matrix for stationary state (35) is defined as

$$
J\left(E_{b}\right)=\begin{array}{|c|c|}
\hline-e m u_{b}<0 & r u_{b}>0 \\
\hline-k m(1-\delta) v_{b}<0 & k m \mu\left(1-u_{b}\right) v_{b} \\
\hline
\end{array}
$$

This matrix shows besides 'intra-specific' competition for relative wage an appearing of stabilizing 'intra-specific' competition for jobs for $\mu<0$ additionally as both $\frac{\partial \dot{u}}{\partial u}<0$ and $\frac{\partial \dot{v}}{\partial v}<0$ at the stationary state.

Proposition 3. For $\mu<\mu_{e}$ in (94) stationary state (35) is (a) locally asymptotically stable and (b) hyperbolic.

Corollary. The restriction $\mu<0$ is necessary and sufficient for local asymptotical stability of the stationary state in M-4 without profit-sharing $(e=0)$ as in simple models in $[9,11]$.

So "neoclassical" policy is always stabilizing in M-4. We see besides that that a successful 'Keynesian' stabilization policy is also possible in M-4 entirely due to profit sharing for $e>0$ if $0<\mu<\mu_{e}$. This result is new in relation to [9-11] that do not take profit-sharing into account.

Proposition 4. Andronov - Hopf bifurcation happens in this system of (14) and (34) at $\mu=\mu_{g}$ in (98) if $\mu_{g}<\mu_{h}=\frac{(1-\delta) r}{e m\left(1-u_{b}\right)}$ in (97).

Figure 6 displays dynamics in M-4 in result of AndronovHopf bifurcation compared with self-sustained oscillations around a neutral center in M-1.

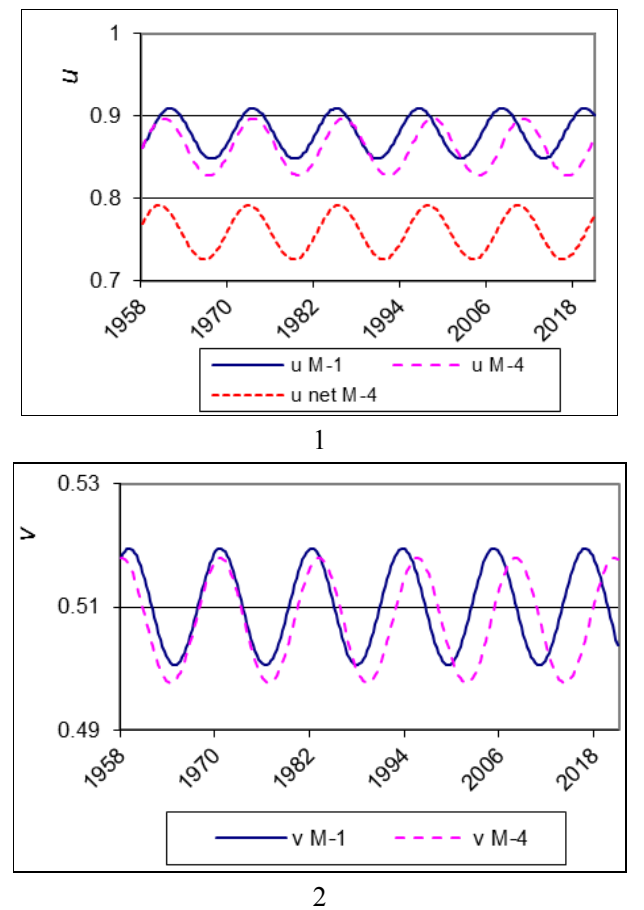

Figure 6. Comparison of conservative fluctuations in M-1 with self-sustained fluctuations in M-4, 1958-2021: relative wage $u$ (panel 1) and employment ratio $v$ (panel 2)
The simulation runs apply common initial conditions and parameters: $u_{0}=0.8623, v_{0}=0.5180 ; \quad g=1, h=0.02, k=$ $1, \quad m=0.33, n=0.02, r=2$, additionally $e=0.1, d=0.12$ and $\mu=\mu_{g}=1.2329$ in M-4; stationary magnitudes are $u b(1-\delta)=0.7588<u b=0.8623<u_{G}=0.8788$ and $v b \approx$ $0.5077<v_{G}=0.51$; period of growth cycle: $T_{M-4}\left(\mu_{g}\right)=$ $12.48>T_{M-1}=11.55$.

Thus profit-sharing can typically stabilize instability resulting from 'Keynesian' policy with $0<\mu \leq 3$ (taken for certainty $k=1,0.1 \leq \delta \leq 0.5$ ). Still we ought not to forget about the above "capricious" investment function and flexible rate of production capacity utilization that aggravate the difficulty of the stabilization problem in a model that follows.

\subsection{Complication of the Stabilization Problem Due to "Capricious" Investment Function in M-5}

My central result in this subsection: "Keynesian" fiscal policy will destabilize capital accumulation in three-dimensional model while a sufficiently strong "neoclassical" policy will do the opposite. This is already observed in [11], although for different models that are theoretically less accurate than the present one because of their confusion between productive and fictitious capital as noticed already above.

Government taxes and expenditures introduced in subsection 3.1 affect the former investment function. This becomes more complicated. In result the complexity of a newly constructed model is grown tremendously. This model retains "animal spirits" contained in M-3 that manifests itself in rather high magnitudes of $\varepsilon$ relative to $d$.

Now the intensive form of the modified model M-5 including the renewed investment function consists of the following three non-linear ODEs:

$$
\begin{gathered}
\dot{u}=[-g+r v+e m x(1-u)-h] u, \\
\dot{v}=(\hat{K}-d+\hat{x}) v= \\
{\left[k x\left(1-\delta_{1}\right)(1-u) m-d+\hat{x}\right] v,} \\
\dot{x}= \\
\frac{\varepsilon(d-1+x-\hat{K})+\dot{u}\left(1-\delta_{1}\right) k m x-(1-u) k m x \mu(\hat{K}-d) v}{(1-u) k m\left(1-\delta_{1}+\mu v\right)}= \\
\frac{1}{(1-u)\left(1-\delta_{1}+\mu v\right)} . \\
{\left[\dot{u}\left(1-\delta_{1}\right)-(1-u) \mu(\hat{K}-d) v+\frac{\varepsilon}{k m x}(d-1+x-\hat{K})\right] x .}
\end{gathered}
$$

Notice that the important feature of (41) is a possibility of singularity detrimental for stability when $1-\delta_{1}+\mu v=0$ that requires $\mu<0$.

Parameters $\delta$ and $\mu$ should be chosen within safe and sound margins. It is hardly possible without prior simulations, here policy tests by Vensim are very helpful indeed.

The system (39)-(41) has stationary state

$$
S_{b}=\left(u_{b}, v_{b}, x_{b}\right),
$$


where $u_{b}$ and $v_{b}$ are the same as those in (35), $x_{b}=1$.

Partial derivatives of growth rate of fixed capital $\hat{K}=$ $k(1-u)\left(1-\delta_{1}\right) m x$ for $\delta_{1}=\delta+\mu\left(v_{b}-v\right)$ and $\dot{\delta}_{1}=-\mu \dot{v}$ with respect to the phase variables in Tables 3 and 4 will be helpful. Notice that $\operatorname{sgn}\left(\frac{\partial \hat{K}}{\partial v}\right)=\operatorname{sgn}(\mu)$.

Table 3. Partial derivatives of growth rate of fixed capital in M-5

\begin{tabular}{|c|c|c|}
\hline$\frac{\partial \hat{K}}{\partial u}$ & $\frac{\partial \hat{K}}{\partial v}$ & $\frac{\partial \hat{K}}{\partial x}$ \\
\hline$-k\left(1-\delta_{1}\right) x m<0$ & $k x \mu(1-u) m$ & $k\left(1-\delta_{1}\right)(1-u) m>0$ \\
\hline
\end{tabular}

Table 4. Partial derivatives of growth rate of fixed capital at stationary state (42)

\begin{tabular}{|c|c|c|}
\hline$\frac{\partial \hat{K}}{\partial u}$ & $\frac{\partial \hat{K}}{\partial v}$ & $\frac{\partial \hat{K}}{\partial x}$ \\
\hline$-k(1-\delta) m<0$ & $\mu d \frac{1}{1-\delta}$ & $d>0$ \\
\hline
\end{tabular}

The Jacobi matrix for stationary state (42) of system (39)-(41) is defined as

$J\left(S_{b}\right)=$\begin{tabular}{|l|l|l|}
\hline$J_{11}$ & $J_{12}$ & $J_{13}$ \\
\hline$J_{21}$ & $J_{22}$ & $J_{23}$ \\
\hline$J_{31}$ & $J_{32}$ & $J_{33}$ \\
\hline
\end{tabular}

The particular elements of this matrix follow together with their typical signs for $\mu<\mu_{b}$ :

$$
\begin{aligned}
& J_{11}=-e m u_{b}<0, J_{12}=r u_{b}>0, J_{13}=e m\left(1-u_{b}\right) u_{b}>0 \\
& J_{21}=-k(1-\delta) m v_{b}+\frac{\partial \hat{x}}{\partial u} v_{b} \\
& =-k(1-\delta) m v_{b} \\
& +\frac{1}{\left(1-u_{b}\right)\left(1-\delta+\mu v_{b}\right)}\left[-e m u_{b}(1-\delta)+\mu d v_{b}+\varepsilon(1-\delta)\right] v_{b}<0 \\
& J_{22}=k m \mu\left(1-u_{b}\right) v_{b}+\frac{\partial \hat{x}}{\partial v} v_{b} \\
& =k m \mu\left(1-u_{b}\right) v_{b} \\
& +\frac{1}{\left(1-u_{b}\right)\left(1-\delta+\mu v_{b}\right)} \\
& {\left[r u_{b}(1-\delta)-\left(1-u_{b}\right) \frac{d}{1-\delta} v_{b} \mu^{2}-\varepsilon \mu\left(1-u_{b}\right)\right] v_{b}<0} \\
& J_{23}=k(1-\delta)\left(1-u_{b}\right) m v_{b}+\frac{\partial \hat{x}}{\partial x} v_{b}=
\end{aligned}
$$

$k(1-\delta)\left(1-u_{b}\right) m v_{b}$

$+\frac{1}{\left(1-u_{b}\right)\left(1-\delta+\mu v_{b}\right)}\left[e \frac{d}{k} u_{b}-\left(1-u_{b}\right) \mu d v_{b}+\frac{\varepsilon}{k m}(1-d)\right] v_{b}<0$, $J_{31}=$

$$
\begin{aligned}
& \frac{1}{\left(1-u_{b}\right)\left(1-\delta+\mu v_{b}\right)} \cdot\left[\frac{\partial \dot{u}}{\partial u}(1-\delta)-\left(1-u_{b}\right) \mu \frac{\partial \hat{K}}{\partial u} v_{b}-\frac{\varepsilon}{k m x} \frac{\partial \hat{K}}{\partial u}\right] \\
& =\frac{1}{\left(1-u_{b}\right)\left(1-\delta+\mu v_{b}\right)} . \\
& {\left[- \text { emu }_{b}(1-\delta)+\left(1-u_{b}\right) \mu d \frac{1}{1-u_{b}} v_{b}+\frac{\varepsilon}{k m x} d \frac{1}{1-u_{b}}\right]=}
\end{aligned}
$$$$
\frac{1}{\left(1-u_{b}\right)\left(1-\delta+\mu v_{b}\right)} \cdot\left[-e m u_{b}(1-\delta)+\mu d v_{b}+\varepsilon(1-\delta)\right]<0,
$$$$
J_{32}=\frac{1}{\left(1-u_{b}\right)\left(1-\delta+\mu v_{b}\right)} \text {. }
$$$$
\left[\frac{\partial \dot{u}}{\partial v}(1-\delta)-\left(1-u_{b}\right) \mu \frac{\partial \hat{K}}{\partial v} v_{b}-\frac{\varepsilon}{k m x} \frac{\partial \hat{K}}{\partial v}\right]=
$$$$
\frac{1}{\left(1-u_{b}\right)\left(1-\delta+\mu v_{b}\right)} \text {. }
$$$$
\left[r u_{b}(1-\delta)-\left(1-u_{b}\right) \mu^{2} d \frac{1}{1-\delta} v_{b}-\frac{\varepsilon}{k m x} \mu d \frac{1}{1-\delta}\right]=
$$$$
\frac{1}{\left(1-u_{b}\right)\left(1-\delta+\mu v_{b}\right)} \text {. }
$$$$
\left[r u_{b}(1-\delta)-\left(1-u_{b}\right) \mu^{2} d \frac{1}{1-\delta} v_{b}-\frac{\varepsilon}{k m x} \mu d \frac{1}{1-\delta}\right]<0,
$$

$J_{33}=\frac{1}{\left(1-u_{b}\right)\left(1-\delta+\mu v_{b}\right)}$.

$\left[\frac{\partial \dot{u}}{\partial x}(1-\delta)-\left(1-u_{b}\right) \mu \frac{\partial \hat{K}}{\partial x} v_{b}+\frac{\varepsilon}{k m}\left(1-\frac{\partial \hat{K}}{\partial x}\right)\right]=$

$\frac{1}{\left(1-u_{b}\right)\left(1-\delta+\mu v_{b}\right)} \cdot\left[e \frac{d}{k} u_{b}-\left(1-u_{b}\right) \mu d v_{b}+\frac{\varepsilon}{k m}(1-d)\right]<0$.

Instability in M-5 is cured mostly by appearance of negative multiplier $\frac{1}{1-\delta+\mu v_{b}}$ on the main diagonal in Jacobi matrix $J\left(S_{b}\right)$. Singularity mentioned above reveals itself again in all the elements of Jacobi matrix $J\left(S_{b}\right)$ already for $\mu$ infinitesimally close to

$$
\mu_{b}=\frac{\delta-1}{v_{b}}<0 .
$$

Ultra-instability is typical for $\mu=\mu_{b}$. The region of stability is such that $-\mu_{\max }=-3<\mu<\mu_{b}<0<\mu_{\max }=3$.

Proposition 5 . For $\mu<\mu_{b}$ stationary state (42) is (a) locally asymptotically stable and (b) hyperbolic.

Corollary. For $e=0$, as in M-1, Proposition 5 remains true.

Figure 7 reflects the condensed causal loop structure of M-5 with polarity typical for a vicinity of the stationary state (42). 


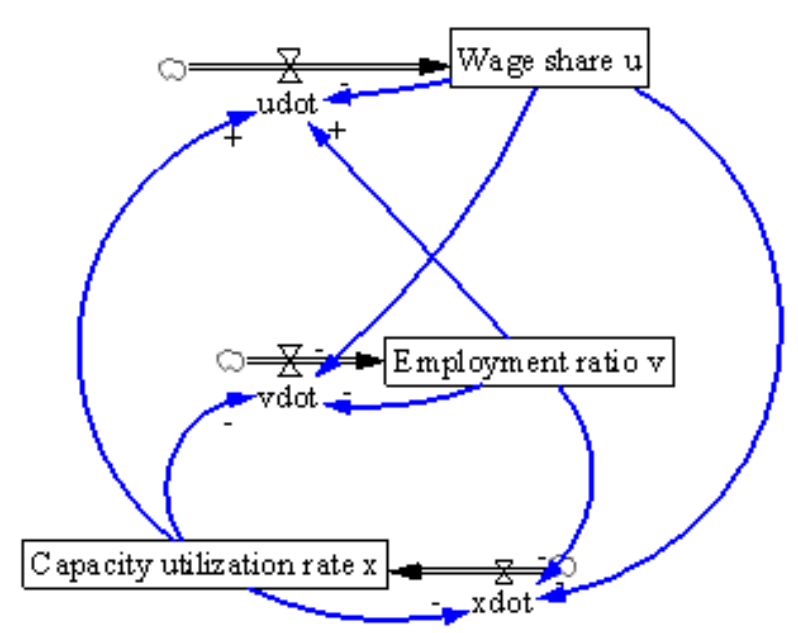

Figure 7. A condensed causal loop structure of M-5 for $\mu<\mu_{b}$ near a stationary state; total number of feedback loops -8 , among them: $1^{\text {st }}$ order 3 negative, $2^{\text {nd }}$ order -3 ( 2 negative and 1 positive $), 3^{\text {rd }}$ order -2 positive

The elements of this Jacobi matrix including those on the main diagonal are negative except the pair in the first row $\left(J_{12}>0\right.$ and $J_{13}>0$ ). So M-5 (for $\mu<\mu_{b}$ ) does belong to Goodwin-type (predator-prey) models - contrary to M-3 and similar to M-2 and M-4.

Simulations have revealed that although two parameters $a_{1}$ and $a_{2}$ of a characteristic equation can be positive for $\mu>0$, the third one $a_{0}<0$ - therefore stability of a stationary state is not amenable to a "Keynesian" policy even under profit-sharing.

Parametric optimization of stabilization policies is carried out in Vensim. An integral of the absolute deviations of employment ratio $v$ from its stationary magnitude $v_{b}$ over 1958-2021 is minimized taking into account additionally values of penalty function, which prevents excessive deviations of tax rate $\delta_{1}$ from its stationary magnitude $\delta$ :

$$
\operatorname{Minimize}\left[\int_{1958}^{2021}\left|v-v_{b}\right| d t+10^{3} \int_{1958}^{2021}\left|\delta_{1}-\delta\right| d t\right]
$$

subject to

$$
\dot{y}=f(y, \mu, \varepsilon),
$$

where $y_{0}=\left(u_{0}, v_{0}, x_{0}\right)=(0,8268,0,518,1,2), g=1, h=0.02, k$ $=1, m=0.33, n=0.02, r=2, e=0.1, \delta=0.3$, initially $-3 \leq \mu$ $=-2 \leq-2$ and $0,01 \leq \varepsilon=1 \leq 1$.

A policy optimization in Scenario I enabled to find sub-optimal magnitudes of the control parameters: $\mu=-2<$ $\mu_{b} \approx-1.3802, \varepsilon=1$ for $u_{0}=u_{b} \approx 0.8268>u_{b \text { net }} \approx 0.5788, v_{0}=$ $0.5180>v_{b} \approx 0.5071, x_{0}=1.2>x_{b}=1$, whereas the magnitudes of the other parameters remain the same as in M-2. It is checked that the tax rate $\left(0.1855 \leq \delta_{1} \leq 0.3562\right)$ lies in the roughly permissible segment $[0,0.5]$. The restriction $|\mu| \leq 3$ is also satisfied.

The new illustrative magnitude of $\delta$ is higher than its previous one in M-4. Correspondingly, the stationary magnitudes of employment ratio and of relative wage (gross and net) are lower in M-5 than their counterparts in M-4.

Simulations in a rather broad space of parameters mag- nitudes reveal that $\mu_{b}$ from (44) defines extreme upper bound for stability range of $\mu$. Only sufficiently careful and strong "anti-Keynesian" policy for $-\mu_{\max }<\mu<\mu_{b}$ is able to solve the task of stabilization. Thus this paper disproves the claim [9]: "The sign of $\mu$ does not matter. In other words, governments may subscribe to either "Keynesian" or "classical" views concerning effective fiscal stabilization; what matters alone for successful stabilization is the strength, and not the kind of response."

At a deeper level of this critical analysis, we come to a more profound assertion. Both types of neoliberal stabilization policy ("Keynesian" and "anti-Keynesian") are rather deficient because they lead to the stationary employment ratio and relative wage that are both below than their counterparts in M-1. These policies are not appropriate instruments for solving the problem of dynamic inefficiency of capitalism more fairly and successfully.

No conscious vigorous attempt was made in [1,5,9-11] for attaining target employment ratio $X>v_{G}$. We need stronger protection of labor interests. Forestalling economic calamities like the Great Depression or the Great Recession before they start unfolding again is urgent. . "... the aim must be to prevent the emergence of rationally irrational behavior. Unless some restrictions are placed on people's actions, they will inevitably revert to it" (see [22]).

\section{Employment-centered Stabilization of Capital Accumulation}

The author has proposed a stabilization policy and reinforced stabilization policy [4]. This section demonstrates that these policies can be developed further for curing the instability generated by the above "capricious" investment function reducing unemployment without aggravating inequality. The recent G20 summit has identified inequality as one of the main things holding the global economy back [20].

\subsection{An Alternative Design of Profit-sharing and Rein- forced Stabilization Policy in R-1}

According to the key assumption on the alternative pro-labor stabilization policy, owners of capital, State officials under pressure of workers parties, trade-unions and grass-root organizations set a target growth rate of profit depending on the difference between the indicated $X_{1}$ and current $v$ employment ratios taking into account the growth rate of production capacity utilization $\hat{x}$ :

$$
\hat{M}=-\frac{\dot{u}}{1-u}+\hat{K}+\hat{x}=c_{2}\left(X_{1}-v\right),
$$

where $c_{2}>0, v<X_{1}=X+\frac{d}{c_{2}}, X$ denotes the target employment ratio, absent in the previous models from M-1 to $\mathrm{M}-5, d$ is the stationary economic growth rate as before. Information delays are not taken into account again in this equation implying proportional control. 
The reinforced stabilization policy in R-1 modifies the latter equation by adding an element of derivative control for $q>1$ :

$$
\hat{M}=c_{2}\left(X_{1}-v\right)+(1-q) \hat{v} .
$$

The intensive form of R-1 consists of three non-linear ODEs (48), (25) and (50). The first of them follows from (25) and (47):

$$
\begin{gathered}
\dot{u}=\left[c_{2}(v-X)+q \hat{v}\right](1-u)= \\
\left\{c_{2}(v-X)+q[k m x(1-u)-d+\hat{x}]\right\}(1-u) .
\end{gathered}
$$

Equation (25) is taken from M-3. The third ODE (50) can be derived through the chain of transformations starting with (23):

$$
\begin{aligned}
& \hat{x}=\frac{1}{1-u}\left[\dot{u}+\frac{\varepsilon}{k m x}(d-1+x-\hat{K})\right] \\
& =\frac{\dot{u}}{1-u}+\frac{\varepsilon}{(1-u) k m x}(d-1+x-\hat{K}) \\
& =\left[c_{2}(v-X)+q \hat{v}\right]+\frac{\varepsilon}{(1-u) k m x}(d-1+x-\hat{K}) \\
& =\frac{\varepsilon}{(1-u) k m x}(d-1+x-\hat{K}) \\
& +c_{2}(v-X)+q[k m x(1-u)-h-n+\hat{x}] \\
& =\frac{c_{2}(v-X)+q[k m x(1-u)-d]}{1-q} \\
& +\frac{\varepsilon}{(1-u)(1-q) k m x}(d-1+x-\hat{K}) .
\end{aligned}
$$

Finally after multiplication of both sides by $x$ we get the third ODE as

$$
\begin{gathered}
\dot{x}=\frac{c_{2}(v-X)+q(\hat{K}-d)}{1-q} x \\
+\frac{\varepsilon}{(1-u)(1-q) k m}(d-\hat{K}+x-1),
\end{gathered}
$$

where $\hat{K}=k(1-u) m x$ as in $\mathrm{M}-3$.

\section{A Non-trivial Stationary State}

The positive stationary state for the system of ODEs (48), (25) and (50) is defined as

$$
S_{X}=\left(u_{a}, X, x_{a}\right)
$$

where $u_{a}=u_{G}$ is taken from (26) of M-3, the stationary (target) employment ratio $X=X_{1}-\frac{d}{c_{2}}>v_{G}>v_{a}$ and finally the stationary rate of production capacity utilization is identically one $x_{a}=1$ as in M-3. ${ }^{7}$

Recall that in agreement with (3) and (4) that remain op-

\footnotetext{
${ }^{7}$ Similar to M-2 (with exogenous output-capital ratio and exogenous accumulation rate) this model also does not pass the extreme condition test not allowing $u_{a}>0$ for $0 \leq k \leq d / m$.
}

erative in this model

$$
\begin{aligned}
\hat{w} & =\hat{u}+h= \\
& =\hat{w}^{m}+\hat{w}^{b} .
\end{aligned}
$$

Correspondingly the two terms of the total wage growth rate $\hat{w}$ - bargained $\hat{w}^{m}$ and stimulating $\hat{w}^{b}-$ are presented as manifestation of combined proportional and derivative control in the respective elementary forms based on (48) and (52):

$$
\begin{gathered}
\hat{w}^{m}=c_{2}(v-X) \frac{1-u}{u}+c_{1}, \\
\hat{w}^{b}=h+q \hat{v} \frac{1-u}{u}-c_{1},
\end{gathered}
$$

where $c_{1}=$ const $>0$ can be specified, for example, as $c_{1}=$ $h / 2$, then stationary growth rates $\hat{w}_{c}^{m}=\hat{w}_{c}^{b}=h / 2$.

Let us compare (53) and (54) with their analogues (12) and (13) in M-2.

A comparison of (53) to (12) reveals important differences: first, constant $g$ is substituted by the product of new constants $c_{2}, X$ and rate of surplus value $\frac{1-u}{u}$, second, that constant $c_{1}$ is added to this product, third, the constant $r$ is converted into the product of new constant $c_{2}$ and rate of surplus value.

In (54), fourth, the rate of growth of output per worker plays a significant role contrary to equation (13), fifth, the non-linear positive dependence of the growth rate of labor compensation $\hat{w}$ on the growth rate of employment ratio $\hat{v}$, multiplied by the rate of surplus value, has replaced the positive dependence of growth rate of labor compensation on profit rate in equation (13). The addition of constant $c_{1}$ in (53) is compensated by its deduction in (54).

Notice a growing demand for labor is expressed in increasing $v$ and $\hat{v}$. The original Phillips equation includes the elements analogous to $c_{2} v \frac{1-u}{u}$ and $q \hat{v} \frac{1-u}{u}$ but without the rate of surplus value as a multiplier. A question arises: why capitalists can allow this multiplication, above all for $v>X$ in (53) and $\hat{v}>0$ in (54), contrary to their immediate interests?

Of course, labor class struggle with capital for more favorable terms of sale of their labor power provides the explanation that gives logical consistency to the syllogism maintaining (8) as well as (53), (54) and finally (52).

Marx wrote in [24]: “...when competition permits the worker to bargain and to argue with the capitalists, he measures his demands against the capitalists' profit and demands a certain share of the surplus value created by him; so that the proportion itself becomes a real moment of economic life itself. Further, in the struggle between the two classes - which necessarily arises with the development of 
the working class - the measurement of the distance between them, which, precisely, is expressed by wages itself as a proportion, becomes decisively important. The semblance of exchange vanishes in the course [Prozess] of the mode of production founded on capital."

A further expansion of (54) yields

$$
\begin{gathered}
h+q k\left[(1-u) m x-\frac{d}{k}+\frac{\hat{x}}{k}\right] \frac{1-u}{u}-c_{1}= \\
\left(h+q \frac{1-u}{u} \hat{x}\right)+q k\left[(1-u) m x-\frac{d}{k}\right] \frac{1-u}{u}-c_{1} .
\end{gathered}
$$

Besides the profit sharing element in the modified form $q k\left[(1-u) m x-\frac{d}{k}\right] \frac{1-u}{u}$ in (55), there is the new element reflecting a multiplied effect of growth rate of the rate of capacity utilization $q \frac{1-u}{u} \hat{x}$ on wage growth rate. The sum $h+q \frac{1-u}{u} \hat{x}$ in (55) is analogue of an adjusted growth rate of output per worker as if it were dependent on the growth rate of the rate of production capacity utilization that is positively associated with a growth rate of employment ratio.

Factoring rate of surplus value and growth rate of output per worker into the growth rate of labor compensation (52) helps narrow amplitude of cyclical fluctuations of the most important variables, including the employment ratio thus strengthening the counter-cyclical effects of profit-sharing in M-2.

Upgrading profit-sharing improves social efficiency of macroeconomic reproduction, especially in the long term, in R-1 in relation to M-2 and other previous models. As it turns out later, capital will benefit in the long run from these structural changes too.

\section{Asymptotical Local Stability of the Stationary State}

Table 5 plays a supporting role in the current analysis. It contains partial derivatives of $\hat{K}$ with respect to phase variables indispensable for a Jacobi matrix as in the previous similar cases.

Table 5. Partial derivatives of $\hat{K}$ at the stationary state $S_{X}$

\begin{tabular}{|c|c|c|}
\hline$\frac{\partial \hat{K}}{\partial u}$ & $\frac{\partial \hat{K}}{\partial v}$ & $\frac{\partial \hat{K}}{\partial x}$ \\
\hline$-k m=-d \frac{1}{1-u_{a}}$ & 0 & $k\left(1-u_{a}\right) m=d$ \\
\hline
\end{tabular}

For stationary state $S_{X}(51),(56)$ defines Jacobi matrix

$$
\begin{array}{|c|c|c|}
\hline \frac{(\varepsilon-d) q}{1-q} & \frac{c_{2}\left(1-u_{a}\right)}{1-q} & \begin{array}{c}
\frac{q\left(1-u_{a}\right)}{1-q} . \\
\left(d+\frac{\varepsilon}{d}-\varepsilon\right)
\end{array} \\
\hline \frac{(\varepsilon-d) X}{(1-q)\left(1-u_{a}\right)} & \frac{c_{2} X}{1-q} & \frac{X}{1-q} \cdot \\
\left(d+\frac{\varepsilon}{d}-\varepsilon\right)
\end{array}
$$

where for $c_{2}>0$ and $q>1$ the signs of this matrix elements are defined consequently:

$$
\begin{aligned}
& J_{11}<0 \text { if } \varepsilon>d, J_{12}<0, J_{13}<0, \\
& J_{21}<0 \text { if } \varepsilon>d, J_{22}<0, J_{23}<0, \\
& J_{31}<0 \text { if } \varepsilon>q d, J_{32}<0, J_{33}<0 .
\end{aligned}
$$

Realistically $\varepsilon>q d$ and moreover $\varepsilon>d$ thanks to capitalists' "animal spirits" again as in M-3 and M-5. Thus all elements of this Jacobi matrix including those on the main diagonal are typically negative similar to M-5 still without exceptions unlike the former. This model for $c_{2}>0$ and $q>1$, like M-3, is not Goodwinian (predator-prey) model.

Figure 8 presents a condensed causal loop structure of R-1 with loop polarity typical for a vicinity of the stationary state.

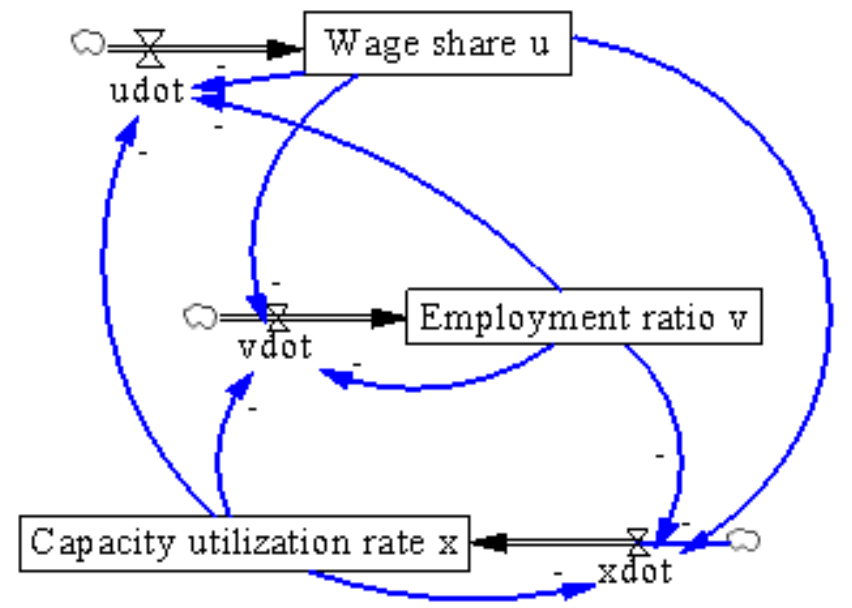

Figure 8. A condensed causal loop structure of R-1 near a stationary state; total number of feedback loops -8 , among them: $1^{\text {st }}$ order -3 negative, $2^{\text {nd }}$ order -3 positive, $3^{\text {rd }}$ order -2 negative

Proposition 6. Stationary state (51) is (a) locally asymptotically stable and (b) hyperbolic. 


\subsection{Higher Efficiency of Reinforced Stabilization Policy in Simulation Experiments}

A policy optimization in Vensim is carried out based on a restricted dynamic optimization problem:

$$
\begin{gathered}
\text { Minimize }\left[\int_{1958}^{2021}|v-X| d t+10^{5} \int_{1958}^{2021} \operatorname{sgn}(v-X) d t\right] \\
\text { subject to } \dot{y}=f\left(y, c_{2}, q, \varepsilon\right),
\end{gathered}
$$

where $y_{0}=\left(u_{0}, v_{0}, x_{0}\right)=(0.8268,0.518,1.2), X=0.95, g=1$, $h=0.02, k=1, m=0.33, n=0.02, r=2$; initially: $0.01 \leq c_{2}=$ $0.4 \leq 1.5,0.5 \leq q=4 \leq 7,0.1 \leq \varepsilon=1 \leq 2$.

The integral of the absolute deviations of employment ratio $v$ from its stationary magnitude $X$ over $1958-2021$ is minimized taking into account additionally values of penalty function, which prevents excessive deviations of employment ratio $v$ from its stationary magnitude $X$.

The normative Scenario II uses sub-optimal magnitudes of the control parameters $c_{2}=0.8823, q=7$ and $\varepsilon=2$. Simulations demonstrate that employment ratio $v$ moves to target $X=$ 0.95 with a very moderate over-shoot whereby $v_{\max }=0.953$. Figures $9-12$ display results that are generally superior to those in M-5 with its sub-optimal $\mu=-2, \varepsilon=1$ in inertia Scenario I from subsection 3.3.

The universal magnitudes of initial conditions and common parameters are the same in Scenarios I and II, besides that the latter outperforms the former in the long run: $u_{a}=u_{G}=$ $0.8788>u_{b} \approx 0.8268, X>>v_{b} \approx 0.5071$.

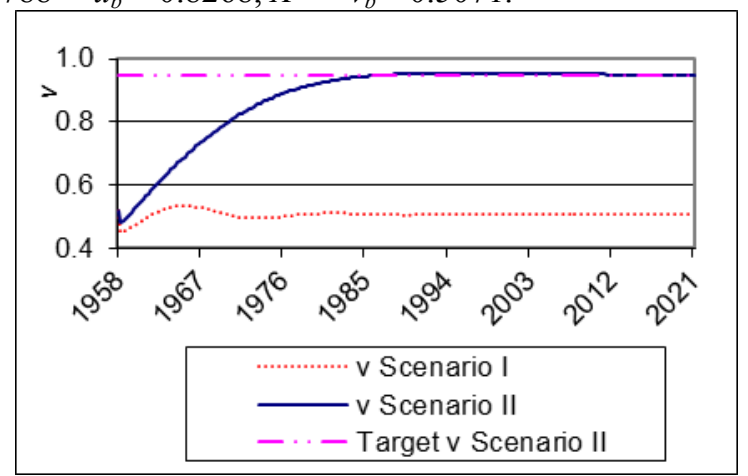

Figure 9. Dynamics for the 'neoclassical' and for reinforced stabilization policies in Scenario I based M-5 and in Scenario II based R-1: employment ratio $v$

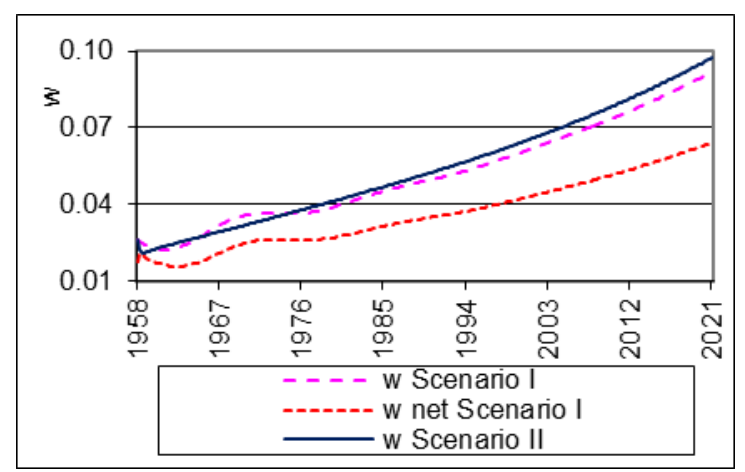

Figure 10. Dynamics for the 'neoclassical' and for reinforced stabilization policies: wage - gross $w$ and net $w\left(1-\delta_{1}\right)-$ in Scenario I based M-5 and wage $w$ in Scenario II based R-1

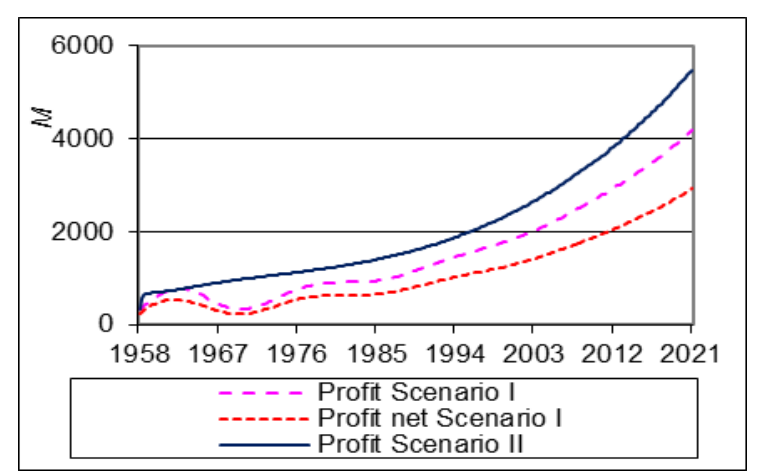

Figure 11. Dynamics for the 'neoclassical' and for reinforced stabilization policies: profit - gross $M$ and net $M\left(1-\delta_{1}\right)$ - in Scenario I based M-5 and profit $M$ in Scenario II based R-1

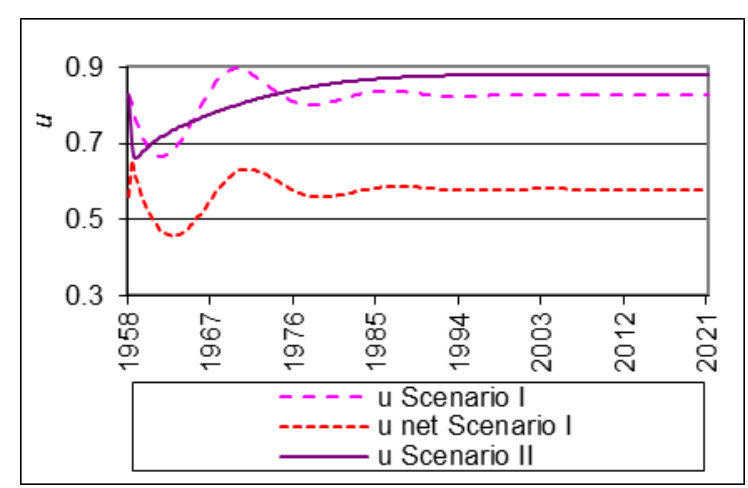

Figure 12. Dynamics for the 'neoclassical' and for reinforced stabilization policies: relative wage - gross $u$, net $u\left(1-\delta_{1}\right)$ - in Scenario I based M-5 and relative wage $u$ in Scenario II based R-1

The questions asked at the end of subsection 2.3 are resolved. First, due to upgraded profit-sharing the dominant positive feedback loops are transformed into negative. More technically, second, two partial derivatives $\frac{\partial \dot{v}}{\partial v}$ and $\frac{\partial \dot{x}}{\partial x}$ estimated at the new stationary state are negative indeed prohibiting self-reinforcing explosive processes contrary to M-3. Third, a 'price' (or better 'prize') of this conversion is a strong gain in a long-term employment ratio $v$ as well as strong monotonous growth of profit and surplus value unachievable in the previous five models (from M-1 to M-5).

The reinforced stabilization policy may be rightly called socially efficient in confines of evolving capitalism. Still socially inferior neoliberal policies have a strong hold on the neoliberal economists' minds and, that is more important, on neoliberal policies [7].

As reports from the ILO and IMF have demonstrated $[25,26]$, the decline in power and influence of trade unions has accelerated the growth of inequality. In particular, [26] identifies that declining trade unionism accounts for $40 \%$ of the growth in inequality - the largest single causative element. Strengthening labor market institutions, redistribution and collective bargaining are indispensable in tackling inequality and unsustainable growth as two sides of the same coin. 


\section{Maintaining Capital Accumulation through Excess Income Levy}

The definition of balanced government taxes and expenditures in subsection 3.1 creates the logical difficulty already for $\delta=0$ and $\mu \neq 0$ in (27):

$$
T=G=\delta_{1} P=\mu\left(v^{*}-v\right) P=\mu\left(v^{*}-v\right) w L+\mu\left(v^{*}-v\right) M,
$$

where $T=G<0$ is possible either for $\mu<0$ and $v^{*}>v$ or for $\mu>0$ and $v^{*}<v$ in contradiction to requirement $T=G \geq 0$. This formal contradiction is difficult for noticing particularly due to no dependence of the stationary states in M-4 and M-5 on $\mu$.

The neoliberal approach to stabilizing growth cycle practically requires $\delta>0$ as margin of safety. This parameter is the higher, the higher are $|\mu|$ and $\left|v^{*}-v\right|$ or the latter both with detrimental consequences for long-term social efficiency.

Without substantial State parasitism neoliberal stabilization is impossible in M-4 and even more so in M-5. This parasitism is maintained by the elevated long-term gross rates of surplus value and profit defined according to (35) and (42). Quite differently, the pro-labor consistent critical stance on this paramount issue envisages a persistent reduction of parasitic government taxes and expenditures up to their complete abolishing. This course enables reduction of the long-term rates of surplus value and profit that cannot happen without successful class struggle of labor against capital. Unfortunately, the recent ILO and IMF documents
$[25,26]$ as well as G20 policy priorities on labor income share and inequalities [20] are silent on this critical issue.

I will abstract from socially necessary government taxes and expenditures that are not parasitic. Then a reasonable solution suggests itself.

A sufficient condition for balanced budget in the absence of parasitic government taxes and expenditures is satisfied if levies are counteracted by subsidies: first, by allowing two parameters at gross wage $w L$ and at gross profit $M$ with opposite sign instead of single $\mu$, second, by treating both as variables depending on other main variables.

\subsection{Reinforced Stabilization Policy in a Reduced Model without the Investment Function X-1}

Let us step back and introduce $\mathrm{X}-1$ as a two-dimensional case of R-1 consisting of (59) for $\dot{u}$ :

$$
\dot{u}=\left\{c_{2}(v-X)+q[k m(1-u)-d]\right\}(1-u)
$$

and (15) for $\dot{v}$. Figure 13 and Table 6 display the extensive causal loop structure of $\mathrm{X}-1$. This structure almost retains the former two negative feedback loops B1 and B2 of M-2 yet without profit rate.

Besides, there are two new loops - one negative B3, containing employment ratio and relative wage, as well as one positive $\mathrm{R} 1$ (for $v<X$ ) including relative wage. Both new feedback loops (as expected in relation to B3 still surprisingly in relation to R1) strengthen stability of capital accumulation. Notice that R1 turns into negative feedback loop B4 for $v>X$, these both are not active for $v=X$.

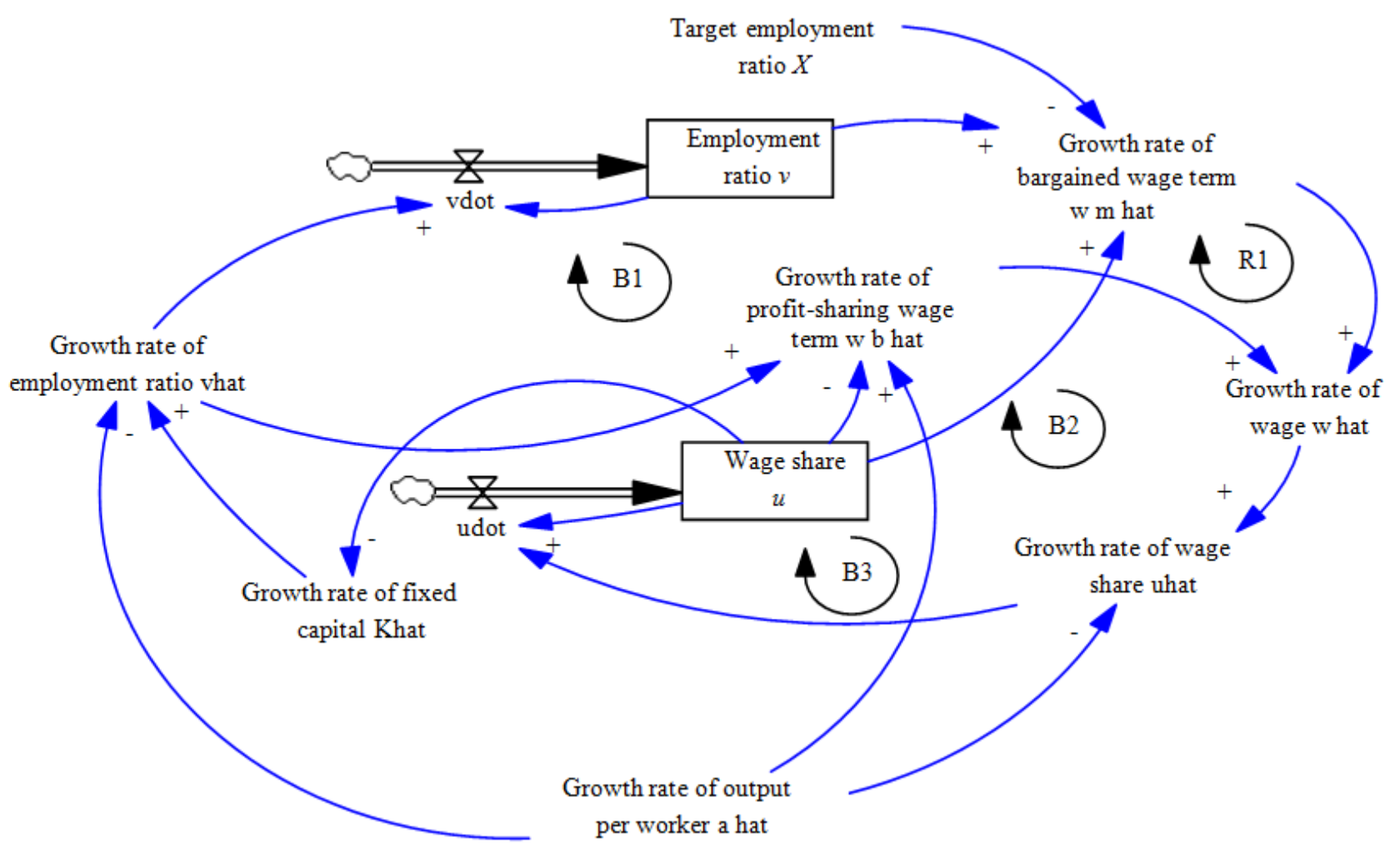

Figure 13. A causal structure of $\mathrm{X}-1$ (assuming $v<X$ for certainty) 
Table 6. Four main feedback loops in X-1

\begin{tabular}{|c|c|}
\hline Loops descendant from M-2 & New loops \\
\hline $\begin{array}{c}\text { B1 of length } 8 \\
\text { Wage share } u \stackrel{-}{\text { GR fixed capital }} \\
\text { GR employment ratio } \\
\text { Net change of } v \\
\text { Employment ratio } v \\
\text { GR bargained wage term } \\
\text { GR wage } \\
\text { GR wage share } \\
\text { Net change of } u \\
\end{array}$ & $\begin{array}{c}\text { B3 of length } 6 \\
\text { Wage share } u \stackrel{-}{\longrightarrow} \\
\text { GR fixed capital } \\
\text { GR employment ratio } \\
\text { GR profit sharing wage term } \\
\text { GR wage } \\
\text { GR wage share } \\
\text { Net change of } u\end{array}$ \\
\hline $\begin{array}{c}\text { B2 of length } 4 \\
\text { Wage share } u \stackrel{-}{\longrightarrow} \\
\text { GR profit sharing wage term } \\
\text { GR wage } \\
\text { GR wage share } \\
\text { Net change of } u\end{array}$ & $\begin{array}{l}\text { R1 of length } 4 \text { (for } v<X \text { ) } \\
\text { Wage share } u \\
\text { GR bargained wage term } \\
\text { GR wage } \\
\text { GR wage share } \\
\text { Net change of } u\end{array}$ \\
\hline
\end{tabular}

Note. As M-2, X-1 includes additionally two $1^{\text {st }}$ order feedback loops for relative wage $u$ and employment ratio $v$ with alternating polarity. GR is for "growth rate of".

For the system of two ODEs (59) and (15) that determine the intensive form of $\mathrm{X}-1$ the Jacobi matrix is defined as

$$
J_{X-1}=\begin{array}{|c|c|}
\hline-\frac{\dot{u}}{1-u}-q k m(1-u) & c_{2}(1-u) \\
\hline-k m v & \hat{v} \\
\hline
\end{array}
$$

We see X-1 belongs to Goodwin-type (predator-prey) models as $\frac{\partial \dot{v}}{\partial u}<0$ and $\frac{\partial \dot{u}}{\partial v}>0$ similar to M-2 and M-4.

It has the non-trivial stationary state as a two-dimensional case of $S_{X}(51)$ :

$$
E_{X}=\left(u_{a}, X\right) .
$$

Proposition 7 (a). The stationary state $E_{X}(61)$ is locally asymptotically stable.

Proposition 7 (b). If $0<c_{2} \leq c_{2}^{q}$ the stationary state $E_{X}(61)$ is stable node; otherwise it is stable focus. In both cases it is hyperbolic.

Again the integral of the absolute deviations of employment ratio $v$ from its stationary magnitude $X$ over 1958-2021 is minimized taking into account additionally values of penalty function, which prevents excessive deviations of employment ratio $v$ from its stationary magnitude $X$.

A policy optimization in Vensim is carried out based on a restricted dynamic optimization problem:

$$
\operatorname{Minimize}\left[\int_{1958}^{2021}|v-X| d t+10^{5} \int_{1958}^{2021} \operatorname{sgn}(v-X) d t\right]
$$

$$
\text { subject to } \dot{y}=f\left(y, c_{2}, q\right) \text {, }
$$

where $y_{0}=\left(u_{0}, v_{0}\right)=(0.8788,0.518), X=0.95>>v_{0}, g=1, h$ $=0.02, k=1, m=0.33, n=0.02, r=2$; initially: $0.01 \leq c_{2}=0.2$ $\leq 1.5$ and $0.5 \leq q=2 \leq 5$.

The sub-optimal solution for the stable focus implies $c_{2}=$ $0.2558>c_{2}^{q}=0.1684$ and $q=4$. These magnitudes are used in simulations below as well. For them, the period of converging fluctuations is about $T_{X-1}=109.04$.

The convergence of employment ratio $v$ to its distant attractor $X$ is practically monotonous with smoothed out fluctuations. This necessitates a substantial decline in relative wage $u$ for about 10 years initially.

The suggested reinforced stabilization policy is robust in relation to a second order information delay in formation of relative wage [4]. This policy overcomes inefficiency and instability that arise in an augmented four-dimensional modification of M-2 with second order information delay in relative wage formation [1].

\subsection{Excess Income Levy in an Augmented Model R-2}

Consider a novel outline of excess income levy within attainable bounds that may enhance long-term stability of capital accumulation consciously controlled by the State. It suggests the appropriate levy base and appropriate levy rates for primary distribution of income (labor compensation and profit) in an advanced capitalist economy encouraging efficient investment into produced capital, whereby jobs generation serves as engine of more equal and inclusive economic growth than in the above models (from M-2 to M-5).

The notion of excess income levy introduced in [27] is used in this paper as a general notion for the reduction in pre-levy primary income. The term excess labor compensation levy, in particular, is for the reduction in pre-levy primary labor compensation. The counter-part of excess labor compensation levy is subsidy (of the same quantity) on pre-levy primary profit. In the opposite case, excess profit levy equals subsidy on labor compensation receivable. It is the State that can levy surcharges on excessive income of laborers (or capitalists) and pay equivalent subsidy. The State plays here the Maxwell Demon's role. 
For convenience, denote modification of R-1 and X-1 as R-2.

Let $w_{p t}$ is the pre-levy labor compensation taken as the levy base:

$$
w_{p t}=w \frac{1+\hat{w}_{p t}\left[\frac{1}{\text { year }}\right] \cdot 1[\text { year }]}{1+\hat{w}\left[\frac{1}{\text { year }}\right] \cdot 1[\text { year }]} .
$$

Its rate of change $\hat{w}_{p t}$ is determined according to (8) in M-2. The after-levy labor compensation is denoted as before by $w$; its rate of change $\hat{w}$ is determined in its turn by (52) from R-1 based on the above deterministic form of the modified control law of capital accumulation.

The dynamics of capital accumulation in M-2 is interpreted as the inertia scenario. An improvement upon this in $\mathrm{R}-2$ is consequently the normative scenario. Notice that the rate of capital accumulation is the same in both models therefore superior results of the proposed original stabilization policy are not explained by a difference in this rate.

The rate of excess labor compensation levy (as a fraction of unit) is

$$
x_{w}=\left(\hat{w}_{p t}-\hat{w}\right) \cdot 1[\text { year }]
$$

Applying (63) and (64) an equivalent expression for pre-levy labor compensation can be derived:

$$
w_{p t}=w+\frac{w}{1+\hat{w}\left[\frac{1}{\text { year }}\right] \cdot 1[\text { year }]} x_{w}
$$

The overall excess labor compensation levy equals overall subsidy on pre-levy primary profit

$$
T_{w}=\frac{x_{w} w L}{1+\hat{w}\left[\frac{1}{\text { year }}\right] \cdot 1[\text { year }]}=S_{P} .
$$

The total profit is now

$$
P-\left(w_{p t} L-T_{w}\right)=P-w_{p t} L+S_{P}=P-w L .
$$

Using the new stationary employment ratio from (51) and the previous one from (16) we get a rather elegant formula for the stationary relative excess labor compensation levy (as a fraction of unit)

$$
\begin{gathered}
\bar{x}_{w}=\left[\left(\hat{w}_{p t}\right)_{a}-\hat{w}_{a}\right] \cdot 1[\text { year }]= \\
{\left[-g+r X+e m\left(1-u_{a}\right)-(d-n)\right] \cdot 1[\text { year }]=} \\
r\left(X-v_{a}\right) \cdot 1[\text { year }] .
\end{gathered}
$$

The share of excess labor compensation levy in net output (i.e., unit excess income levy) is

$$
x_{P}=\frac{T_{w}}{P}=\frac{S_{P}}{P}=\frac{w L}{P} \frac{x_{w}}{1+\hat{w}\left[\frac{1}{\text { year }}\right] \cdot 1[\text { year }]}=\frac{u x_{w}}{1+\hat{w}\left[\frac{1}{\text { year }}\right] \cdot 1[\text { year }]}
$$

The stationary share of excess labor compensation levy in net output (i.e., unit excess income levy) is

$$
\bar{x}_{P}=\frac{\bar{x}_{w} u_{a}}{1+h\left[\frac{1}{\text { year }}\right] \cdot 1[\text { year }]} .
$$

The stationary relative subsidy on pre-levy primary profit is

$$
\bar{x}_{M}=\frac{\bar{x}_{P}}{1-u_{a}} .
$$

The labor share in net output is higher than 50 per cent in the model under consideration, so the relative subsidy on pre-levy primary profit exceeds relative excess labor compensation levy in this theoretical model in absolute terms.

Relative wage (gross) is the sum of relative wage (net) and share of excess labor compensation levy in net output

$$
\begin{gathered}
u_{p t}=u+x_{P}=u\left[1+\frac{x_{w}}{1+\hat{w}\left[\frac{1}{\text { year }}\right] \cdot 1[\text { year }]}\right]= \\
u\left[\frac{1+\hat{w}_{p t}\left[\frac{1}{\text { year }}\right] \cdot 1[\text { year }]}{1+\hat{w}\left[\frac{1}{\text { year }}\right] \cdot 1[\text { year }]}\right] .
\end{gathered}
$$

Depending on relation between the target employment ratio $X$ and the stationary employment ratio $v_{a}$ there are, ceteris paribus, three cases:

1) if $X=v_{a}$ the all three stationary levy (subsidy) ratios $\bar{x}_{w}, \bar{x}_{M}$ and $\bar{x}_{P}$ are zero;

2) if $X>v_{a}$ these ratios are positive;

3) if $X<v_{a}$ these ratios are negative.

These three cases are a particular manifestation of the employment ratio - relative labor compensation trade-off. In the second, mostly relevant, case, laborers, having a higher stationary employment ratio than in the inertia scenario, pay levy to the State that provides subsidies to capitalists. In the opposite (third) case when the target employment ratio is lower than the stationary employment ratio in the inertia scenario, capitalists pay levy to the State that provides subsidies to laborers. In the first case, when these both employment ratios are equal, the stationary relative levy (subsidy) is zero. Still excess income levy is pertinent even in this case since employment ratio varies on the transient to the stationary state. 
For the relevant previous parameters values, the stationary relative excess labor compensation levy is $\bar{x}_{w}=r\left(X-v_{a}\right) \cdot 1$ [year] $=2(0.950-0.508)=0.884$. The share of excess labor compensation levy in net output is $\bar{x}_{P}=$ 0.762 according to (70). The relative subsidy on primary profit is $\bar{x}_{M}=6.283$ according to (71). These quantities are clearly excessive - mostly due to the very low magnitude of stationary employment ratio $v_{a}=0.508$ in the inertia scenario intended for my extreme condition tests.

Still reasonable refinement could be elaborated. We do not treat the problem as a one-time game between workers and capitalists mediated by the State. This game is repeated. Then co-operative strategies may follow from social adaptive learning. Here the system dynamics modeling is a very helpful tool for accelerating learning.

In my thought experiment, the very process of redistribution of excess income levy by the State will moderate the coefficients of bargained wage term $g$ by capitalists and $r$ by workers (even relatively stronger) in (8) of M-2. Then $x_{w}$ and $x_{p}$ are not as high as in a model without adjustment in $g$ and $r$. In the process of adaptive adjustment the parameters of the linear Phillips equation are substituted: $r_{a d j}$ takes place of $r$, similarly, $g_{a d j}$ takes place of $g$, thus

$$
\dot{r}_{a d j}=\eta\left(r_{\text {stat }}-r_{a d j}\right),
$$

where initially $\left(t_{0}=1958\right) r_{a d j}=r, \eta>0$,

$$
r_{\text {stat }}=z c_{2}\left(1-u_{a}\right) / u_{a} .
$$

In the same way

$$
\dot{g}_{a d j}=\eta\left(g_{\text {stat }}-g_{a d j}\right),
$$

where initially $(t=1958) g_{a d j}=g$,

$$
g_{\text {stat }}=c_{2} X\left(1-u_{a}\right) / u_{a} \text {. }
$$

Then

$$
z=1+\frac{u_{a}}{c_{2} X\left(1-u_{a}\right)}\left(h-\frac{e}{k} d\right) .
$$

For $t \rightarrow \infty$

$$
\begin{gathered}
\frac{g_{a d j}}{r_{a d j}} \rightarrow g_{\text {stat }} / r_{\text {stat }}= \\
{\left[c_{2} X\left(1-u_{a}\right) / u_{a}\right] /\left[z c_{2}\left(1-u_{a}\right) / u_{a}\right]=X / z}
\end{gathered}
$$

and for $x_{p} \rightarrow 0, x_{w} \rightarrow 0$

$$
\hat{w}_{p t} \rightarrow \hat{w}_{a}=-g_{\text {stat }}+r_{\text {stat }} X+e m\left(1-u_{a}\right)=h .
$$

As the relative reduction in $r$ is stronger than in $g$, there is inequality $g_{\text {stat }} / r_{\text {stat }}>g / r$.
Now for adjustment in parameters $g$ and $r, x_{w}$ is determined by (64) and (15) governs $\dot{v}$. Besides that

$$
\begin{gathered}
\hat{w}_{p t}=-g_{a d j}+r_{a d j} v+e m(1-u), \\
\dot{u}=\left(\hat{w}_{p t}-h-\frac{x_{w}}{1[\text { year }]}\right) u .
\end{gathered}
$$

Equation (81) is the universal equivalent form of (59). The intensive form of decomposable four-dimensional model R-2 consists of (59), (15), (73) and (75). It has non-trivial stationary state $R_{X}$ that augments $E_{X}(61)$

$$
R_{X}=\left(u_{a}, X, r_{\text {stat }}, g_{\text {stat }}\right) .
$$

Proposition 8 . Stationary state $R_{X}(82)$ is (a) locally asymptotically stable and (b) hyperbolic in decomposable four-dimensional model R-2.

Consider the supportive results of comparative simulation experiments with M-2 and R-2.

Initial vector $u_{0}=0.8788, v_{0}=0.518$ and magnitudes of the common parameters are the same as before: $g=1, h=0.02, k$ $=1, m=0.33, n=0.02, r=2$; additionally in R-2: $\eta=0.5, c_{2}=$ $0.2558, q=4, z=1.477$, additionally in M-2: $e=0.1$; the stationary magnitudes in M-2 are: $u_{a}=u_{G}=0.8788, v_{a}=$ 0.508 ; the stationary magnitudes in R-2 are: $u_{a}=u_{G}, X=$ $0.95>v_{G}=0.51>v_{a}, r_{\text {stat }}=0.0521, g_{\text {stat }}=0.0335$.

The normative scenario demonstrates a rather fast convergence of the growth rate of pre-levy labor compensation to the growth rate of post-levy labor compensation as well as narrowing difference between the relative excess labor compensation levies $x_{p}$ and $x_{w}$ that converge to zero in a smooth fashion (Figure 14, panels 2 and 4).

The large gain in the employment ratio $v$ due to the reinforced stabilization policy is seen on panel 1, whereas standard profit-sharing provides a higher relative wage $u$ during the transitional period reported on panel 3 .

The analytical and simulation results demonstrate again that the reinforced stabilization policy raises social efficiency. The proposed design for augmenting the two-dimensional intensive form of X-1 within R-2 can be easily generalized for augmenting the three-dimensional system of ODEs (48), (25) and (50) comprising the intensive form of R-1.

Costs of the pre-market co-operation, co-ordination and State coercion neglected above are to be considered in a subsequent research. It will pay a careful attention to the long-standing German system of works councils and worker directors on company boards known as a system of codetermination and to the reasons why works councils have been in decline [28]. 


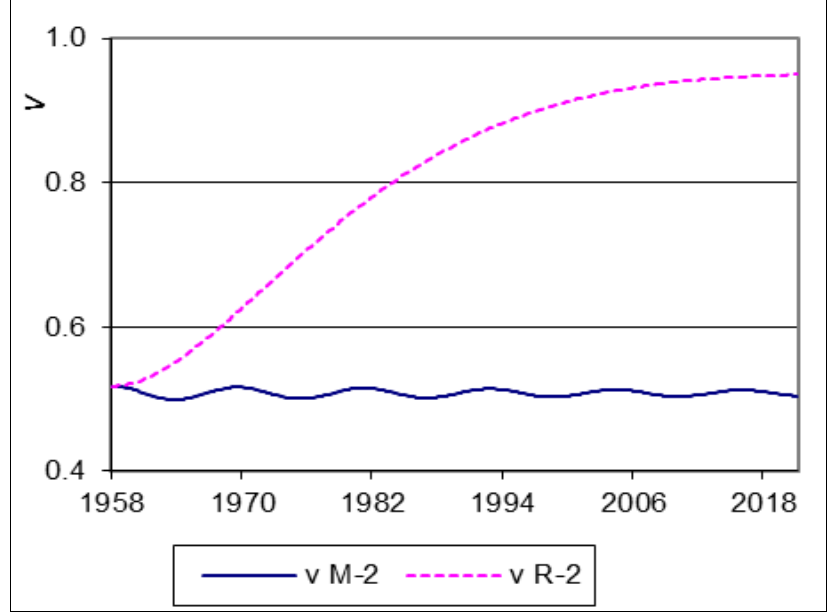

1

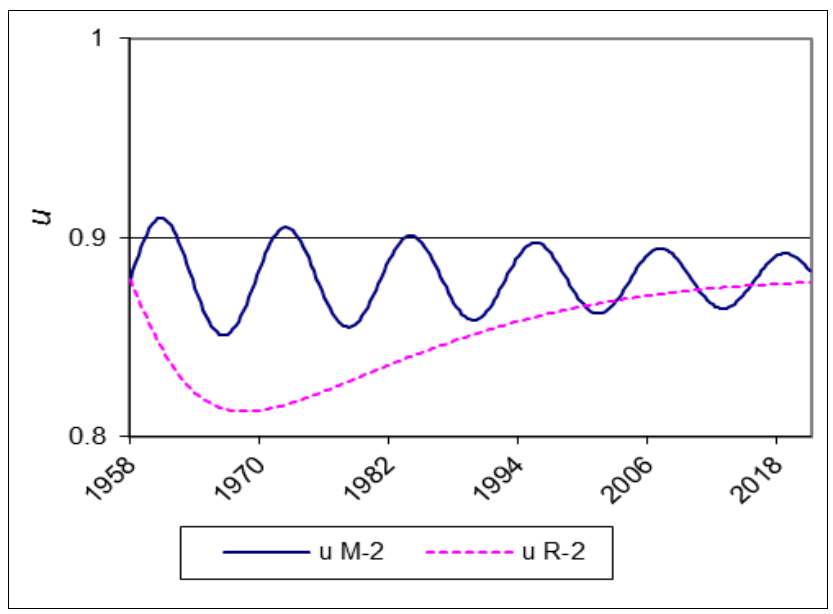

3

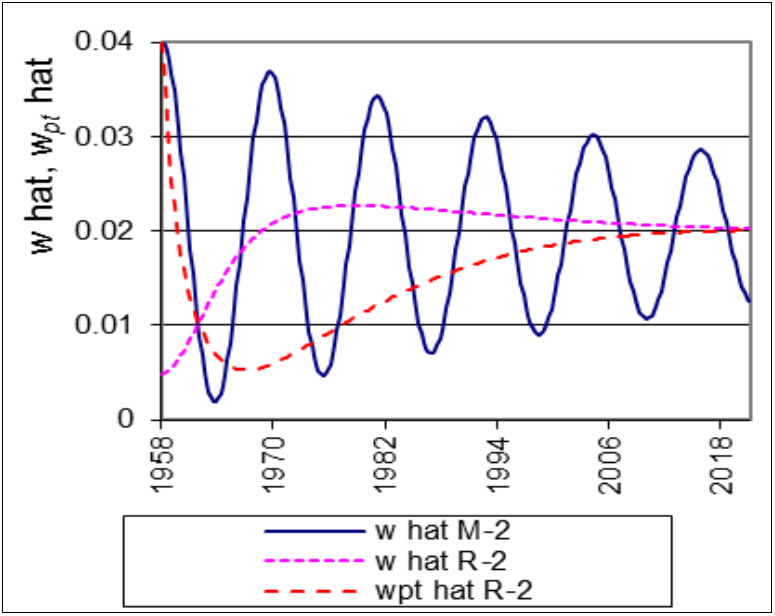

2

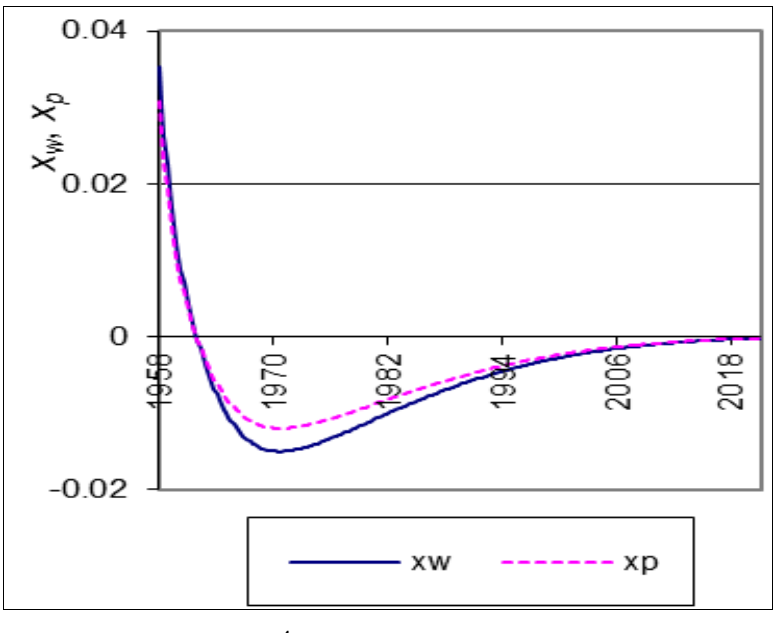

4

Figure 14. Dynamics for standard profit-sharing in inertia scenario in M-2 and reinforced stabilization policy in normative scenario in R-2: panel 1 employment ratio $v$, panel 2 - wage growth rates $\hat{w}$ and $\hat{w}_{p t}$, panel 3 -relative wage $u$, panel 4 -relative excess labor compensation levies $x_{p}$ and $x_{w}$

\section{Conclusions}

This paper demonstrates that government expenditures balanced by taxes are tantamount to cutback of long-term rate of capital accumulation that is usually implicit in M-4 and M-5. This understanding explains the mystery stated in Introduction, namely why government expenditures balanced by taxes in these models reduce stationary gross and net labor shares in national income and can even lessen a long-term employment ratio under standard profit-sharing.

By staging extreme conditions tests with a help of the Phillips - Wolfstetter - Flaschel "capricious" investment function this paper finds out that standard profit-sharing becomes a failed fix in M-3. Stabilization of the "capricious" investment function is achieved in M-5 due to cyclically non-neutral (balanced) government taxes and expenditure. Still this stabilization reduces stationary relative wage compared with that in M-1. Standard profit-sharing (gross) reinforces stabilization thereby yet the stationary employment ratio becomes also lower than that in $\mathrm{M}-1$.
The considered neoliberal critique of "parasitic" State in [9] is rather crafty and inconsistent since the proposed neoliberal stabilization policies (both "neoclassical" and "Keynesian") require wastage of social surplus labor and product. The pro-labor attitude to parasitism is far more critical both in theory and practice.

This investigation has a say about the logic of capitalist economic calamities subject to dominant positive feedback(s). In particular, contrary to the stabilization failure in M-3, the reinforced stabilization policy achieves 'taming of the shrew' by eliminating a destructive dominance of the revealed positive feedback loops in non-Goodwinian R-1.

The key element of reinforced stabilization policy via upgraded profit sharing in R-1 and X-1 or via excess income levy in R-2 is the targeting of deliberately high employment ratio. This policy does not reduce stationary rate of capital accumulation unlike essentially neoliberal stabilization policies 'Keynesian' or "neoclassical'. Thus the reason for lowering stationary employment ratio and stationary labor share in relation to M-1 is eliminated. 
Moreover, these reinforced stabilization policies in R-1, $\mathrm{X}-1$ and R-2 provide superior social efficiency that manifests itself in main economic indicators, including employment, profit, total wage, consumption per head, compared with results in M-1 as well as with outcomes based on standard profit-sharing in M-2, M-4 and M-5. As [30] states, "top priority is timely and effective implementation of growth strategies that include measures to support demand and structural reforms to lift actual and potential growth, create jobs, promote inclusiveness and reduce inequalities."

The research in this paper is maintained by behavior reproduction tests and projections for the economy of the USA compared with the official American projections for the $21^{\text {st }}$ century. Theoretical models from [7] are upgraded thereby by the new definition of reinforced stabilization policy developed for R-1 and X-1; these upgraded models are successfully confronted with updated data [31]. This work deepens the theoretical critique of the dogma of natural rate of unemployment.

The reader sees that the achieved efficient control over social reproduction cannot be complacently taken for granted forever. Its robustness depends primarily on persistence of class struggle and foresightedness of organized working class. Robustness can dialectically turn into fragility if capitalists' investment behavior becomes more vagarious than even the Phillips - Wolfstetter - Flaschel "capricious" investment function suggests. ${ }^{8}$

The measures such as proposed employment targeting, upgraded profit-sharing and excess income levy are politically difficult. Still the author spells these options out theoretically in the belief that opponents will not dismiss them outright as 'inconceivable'.

The supposed two alternative forms of reinforced stabilization policy are not comprehensively designed yet since changes in the wage-setting and other relevant institutions implied by supposed overt closed-loop control over capital accumulation as a whole are not discussed. In particular, it is not elaborated, first, whether such a closed-loop control is to be achieved through coercive and/or voluntary cooperation; second, what arrangement of codetermination, coercion and co-adjustment is mostly suited for providing superior social outcomes depending on particular national conditions and also on globalization trends.

Therefore a future research will be concentrated on further elaborating advanced concrete models with stabilization policies for particular capitalist economies published in $[6,7,27]$ and being prepared for publishing [31]. Confronting utopian economics with reality-based political economy requires plenty of efforts in socio-economic exploration. Practical implications of the proposed stabilization policies can be discussed with interested parties as well.

8 For example, if ceteris paribus capitalists in masse chose $\varepsilon<0$ in R-1, then stationary state $S_{X}(51)$ is unstable since $a_{0}<0$ in (105). This danger can be countered with nationalization of capitalists' assets or pre-empted by real threat of such a radical measure.

Ryzhenkov [29] investigates the problem of fragility of sustainable capital accumulation further taking into consideration proved non-renewable reserves.
For transforming the state-monopoly capitalism progressively, it is minimally necessary, in my view, to place the profits of financial-industrial groups under conscious public control in the interests of working class and whole society.

The organized working class can subdue the market only possessing the State power and commanding highs of the socialist economy and finance. Still even under state-monopoly capitalism, organized working movement and working class struggle can push social and economic development in the proposed direction. The benign and prudent State regulation is imperative thereby.

Workers could even count on support of their completely bourgeois requirements that this paper expresses within upgraded trade unionism from the most visionary representatives of capital - such as the State leaders of F.D. Roosevelt's type, captains of financial capital, predisposed to socially beneficial reformism, progressive managers of insurance and pension funds necessarily projecting over several decades. The optimistic view on this listing could be expanded.

Without recommended overt feed-back control of the social reproduction, attempts to alleviate dynamic inefficiency of capitalism will be far less successful or even doomed to failure. The choice under current circumstances is clear: not between "growth and austerity" but between neoliberal and pro-labor policies as this paper suggests.

A more radical solution (revolutionary transforming capitalist mode of production and transiting to socialism) will be the increasingly stronger (quite conceivable) alternative if the described inferior neoliberal policies remain entrenched.

\section{Appendix A}

A proof of Proposition 1 (a). For the stationary state $E_{a}(16)$ in M-2 (83) defines the Jacobi matrix:

$J\left(E_{a}\right)=$\begin{tabular}{|c|c|}
\hline$-e m u_{a}$ & $r u_{a}$ \\
\hline$-k m v_{a}$ & 0 \\
\hline
\end{tabular}

It has a negative trace and positive determinant. So the Routh - Hurwitz criterion is satisfied. The proof is thus completed. Still additional valuable details can be gained.

A characteristic equation based on (83) is

$$
b_{0} \lambda^{2}+b_{1} \lambda+b_{2}=0,
$$

where

$$
\begin{gathered}
b_{0}=1, \\
b_{1}=-\operatorname{Trace}\left[J\left(E_{a}\right)\right]=e m u_{a}>0, \\
b_{2}=\left|J\left(E_{a}\right)\right|=k m v_{a} r u_{a}>0 .
\end{gathered}
$$

It has two roots with a negative real part

$$
\lambda_{1,2}=-\frac{e m u_{a}}{2} \pm \sqrt{\left(\frac{e m u_{a}}{2}\right)^{2}-k m r v_{a} u_{a}} .
$$


They are real if initially $\left(\frac{e m u_{a}}{2}\right)^{2}-k m r v_{a} u_{a}>0$. Then the stationary state is stable node. Otherwise it is stable focus with a period approximated by

$$
T_{M-2}=2 \pi / \sqrt{k m v_{a} r u_{a}-\frac{\left(e m u_{a}\right)^{2}}{4}} .
$$

Notice $T_{M-2}>T_{M-1}=2 \pi / \sqrt{k m v_{G} r u_{G}}$.

The standard form of a characteristic equation of the third order is written as

$$
\lambda^{3}+a_{2} \lambda^{2}+a_{1} \lambda+a_{0}=0
$$

where the parameters are calculated based on the corresponding values of Jacobi matrix $J_{X}$

$$
\begin{aligned}
& a_{0}=-\left|J_{X}\right|= \\
& -\left(J_{11} J_{22} J_{33}+J_{12} J_{23} J_{31}+J_{21} J_{32} J_{13}-J_{13} J_{22} J_{31}-\right.
\end{aligned}
$$

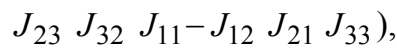

\begin{tabular}{|c|c|c|c|}
\hline \multirow{3}{*}{$J\left(S_{a}\right)=$} & $-e m u_{a}$ & $r u_{a}$ & $e m\left(1-u_{a}\right) u_{a}$ \\
\hline & $\begin{array}{l}\frac{(\varepsilon-d) v_{a}}{1-u_{a}} \\
-\frac{e m u_{a} v_{a}}{1-u_{a}}\end{array}$ & $\frac{r u_{a} v_{a}}{1-u_{a}}$ & $\left.d+\frac{\varepsilon}{d}-\varepsilon\right) v_{a}+e m u_{a} v_{0}$ \\
\hline & $\frac{\varepsilon-e m u_{a}}{1-u_{a}}$ & $\frac{r u_{a}}{1-u_{a}}$ & $\frac{\varepsilon}{d}-\varepsilon+e m u_{a}$ \\
\hline
\end{tabular}

$$
\begin{aligned}
& a_{1}=-\left[J_{23} J_{32}+J_{12} J_{21}+J_{13} J_{31}-J_{11}\left(J_{22}+J_{33}\right)\right. \\
& \text { - } \left.J_{22} J_{33}\right] \text {, } \\
& a_{2}=-\operatorname{Trace}\left(J_{X}\right)=-\left(J_{11}+J_{22}+J_{33}\right) .
\end{aligned}
$$

A proof of Proposition 2 (a) for $M-3$. For stationary state $S_{a}(26)$ in M-3 (88) defines for $k=$ const Jacobi matrix

Parameters of the characteristic equation for Jacobi matrix $J\left(S_{a}\right)$ for stationary state $S_{a}$ are expressed as

$$
\begin{gathered}
a_{0}=-\left|J\left(S_{a}\right)\right|=-\frac{u_{a} v_{a} \varepsilon r}{1-u_{a}}<0, \\
a_{1}=-\varepsilon u_{a}\left(\frac{r v_{a}}{1-u_{a}}+\frac{e m}{d}\right)<0, \\
a_{2}=-\operatorname{Trace}\left[J\left(S_{a}\right)\right]=-\frac{r u_{a} v_{a}}{1-u_{a}}-\frac{\varepsilon}{d}+\varepsilon<0 ;
\end{gathered}
$$

whereas

$$
\begin{gathered}
a_{1} a_{2}-a_{0}=\frac{u_{a} v_{a} \varepsilon r}{1-u_{a}}\left(\frac{r u_{a} v_{a}}{1-u_{a}}+\frac{\varepsilon}{d}-\varepsilon+1\right)+ \\
\frac{\varepsilon e m u_{a}}{d}\left(\frac{r u_{a} v_{a}}{1-u_{a}}+\frac{\varepsilon}{d}-\varepsilon\right) .
\end{gathered}
$$

The Routh - Hurwitz necessary and sufficient conditions for local asymptotic stability of stationary state (26) are violated, as evidenced by (89) - (91).

As $a_{0} \neq 0$, no root equals zero. The inequality $a_{1} a_{2}-a_{0} \neq 0$ excludes supplementing a positive real root by two purely imaginary roots. Consequently, stationary state $S_{a}$ is hyperbolic.

A proof of Corollary to Proposition 2 . Propositions 2 (a) and 2 (b) hold, in particular, true for $e=0$. A proof of Proposition 3 (a) for $M-4$.

The characteristic equation connected to the Jacobi matrix $J\left(E_{b}\right)$ for the stationary state $E_{b}(35)$ in M-4 is defined as

$$
b_{0} \lambda^{2}+b_{1} \lambda+b_{2}=0
$$

where $b_{0}=1$,

$$
\begin{gathered}
b_{1}=-\operatorname{Trace}\left[J\left(E_{b}\right)\right]=e m u_{b}-k m \mu\left(1-u_{b}\right) v_{b}, \\
b_{2}=\left|J\left(E_{b}\right)\right|=k m u_{b} v_{b}\left[(1-\delta) r-e m \mu\left(1-u_{b}\right)\right] .
\end{gathered}
$$

Stationary state $E_{b}$ is asymptotically locally stable if $b_{1}>0$ and $b_{2}>0$. These necessary and sufficient conditions are clearly satisfied for $\mu<0$ even if $e=0$ (no profit-sharing). Still their satisfaction is as well possible for $e>0, b_{1}>0$ and $b_{2}>0$ in (93) if

$$
0 \leq \mu<\mu_{e}=\min \left(\frac{e u_{b}}{k\left(1-u_{b}\right) v_{b}}, \frac{(1-\delta) r}{e m\left(1-u_{b}\right)}\right) .
$$

The roots of the characteristic equation (93) are

$$
\begin{aligned}
& \lambda_{1,2}=\frac{k m \mu\left(1-u_{b}\right) v_{b}-e m u_{b}}{2} \pm \\
& \sqrt{\left[\frac{k m \mu\left(1-u_{b}\right) v_{b}-e m u_{b}}{2}\right]^{2}+k m u_{b} v_{b}\left[e m \mu\left(1-u_{b}\right)-(1-\delta) r\right]} \\
& =\frac{d \mu v_{b}}{2(1-\delta)}-\frac{e m u_{b}}{2} \pm \\
& \sqrt{\left[\frac{d \mu v_{b}}{2(1-\delta)}-\frac{e m u_{b}}{2}\right]^{2}+\frac{e \mu d m u_{b} v_{b}}{1-\delta}-\frac{d r v_{b} u_{b}}{1-u_{b}}} .
\end{aligned}
$$

For a stable focus a period of fluctuations is

$$
T M-4=\frac{2 \pi}{\sqrt{\frac{d r v_{b} u_{b}}{1-u_{b}}-\frac{e \mu d m u_{b} v_{b}}{1-\delta}-\left[\frac{d \mu v_{b}}{2(1-\delta)}-\frac{e m u_{b}}{2}\right]^{2}}} .
$$

Notice that this period is typically longer than the period of conservative fluctuations in $\mathrm{M}-1$ : $T_{M-4}>T_{M-1}=2 \pi / \sqrt{\frac{d r v_{G} u_{G}}{1-u_{G}}}=2 \pi / \sqrt{k m r v_{G} u_{G}}$. For example, for parameters that are the same as before for M-2 above and additionally $\delta=0.12, \mu=-0.5,0.1155 \leq \delta_{1} \leq 0.1251$, we get $T_{M-4}=12.46>T_{M-2}=11.57>T_{M-1}=11.55$ for $u_{b}=1-\frac{d}{k(1-\delta) m}=0.8623<u_{G}=1-\frac{d}{k m}=0.8787<1, v_{b}$ $=0.5077<v_{a}=v_{G}=0.51$.

I omit a clear proof of Corollary to Propo- 
sition 3 .

A proof of Proposition 4 for $M-4$.

Consider $\mu$ as the bifurcation (control) parameter. The stationary state $E_{b}(35)$ is independent of $\mu$.

Let $b_{2}>0$ in (93) that requires

$$
\mu<\mu_{h}=\frac{(1-\delta) r}{e m\left(1-u_{b}\right)} \leq \mu_{e} .
$$

Characteristic equation (93) for $b_{1}=0$ has two purely imaginary roots at the magnitude of control parameter

$$
\begin{gathered}
\mu_{g}=\frac{e u_{b}}{k\left(1-u_{b}\right) v_{b}} \\
\text { if } \mu_{g}<\mu_{h} .
\end{gathered}
$$

The transversality condition of the Hopf theorem is satisfied at $\mu_{g}$ :

$$
\begin{aligned}
& \frac{\partial \operatorname{Re} \lambda_{1}(\mu)}{\partial \mu}=\frac{\partial \operatorname{Trace}\left[J\left(E_{b}\right)\right] / 2}{\partial \mu}= \\
& \frac{k m\left(1-u_{b}\right) v_{b}}{2}=\frac{d v_{b}}{2(1-\delta)}>0 .
\end{aligned}
$$

Thus, a simple Andronof - Hopf bifurcation takes place at $\mu_{g}<\mu_{h}$. A period of closed orbit is about

$$
\begin{aligned}
& T_{M-4}\left(\mu_{g}\right) \approx 2 \pi / \operatorname{Im}\left(\lambda_{1}\right)= \\
& \frac{2 \pi}{\sqrt{k m u_{b} v_{b}(1-\delta) r-e\left(m u_{b}\right)^{2}}}, \\
& \text { where } T_{M-4}\left(\mu_{g}\right)>T_{M-1} .
\end{aligned}
$$

For the same illustrative data $\mu_{g}=1.232<\mu_{\max }=3,0.1073$ $\leq \delta_{1} \leq 0.1323$ with period $T_{M-4}\left(\mu_{g}\right) \approx 12.48$ (Figure 6). This Andronov - Hopf bifurcation is super-critical.

It follows from an economic restriction $e<k h / d$ [4] and (98) that maximal $\mu_{g}<\frac{h}{d} \frac{u_{b}}{\left(1-u_{b}\right) v_{b}}$. For the same parameters as before maximal $\mu_{g} \approx 6.162$ that is outside the permissible (roughly determined) economic interval, $-3 \leq \mu \leq$ $\mu_{\max }=3$.

A proof of Proposition 5 (a) for $M-5$.

The roots of the characteristic equations for Jacobi matrix $J\left(S_{b}\right)$ expressed for $\mu<\mu_{b}$ as

$$
\begin{gathered}
a_{0}=\frac{\varepsilon u_{b} v_{b}}{1-\delta+\mu v_{b}}\left[e m \mu-\frac{r(1-\delta)}{1-u_{b}}\right]>0 \\
a_{1}=\frac{\varepsilon}{1-\delta+\mu v_{b}} \\
{\left[\mu v_{b}-\frac{r(1-\delta) u_{b} v_{b}}{1-u_{b}}+e m u_{b}\left(\mu v_{b}-\frac{1-\delta}{d}\right)\right]>0} \\
a_{2}=\frac{1}{1-\delta+\mu v_{b}}
\end{gathered}
$$

$$
\left[\left(\varepsilon+e m u_{b}\right) \mu v_{b}-\frac{r(1-\delta) u_{b} v_{b}}{1-u_{b}}-\left(\frac{\varepsilon}{d}-\varepsilon\right)(1-\delta)\right]>0
$$

because $\frac{1}{1-\delta+\mu v_{b}}<0$ in (101)-(103); in addition, all the elements in square brackets and their algebraic sums are negative. Left is checking out $a_{1} a_{2}-a_{0}>0$ for $\mu<\mu_{b}$. The sign is confirmed when all terms considered separately and together:

$$
\begin{gathered}
a_{1} a_{2}-a_{0}= \\
\frac{\varepsilon}{\left(1-\delta+\mu v_{b}\right)^{2}} \cdot \\
{\left[-\frac{r(1-\delta) u_{b} v_{b}}{1-u_{b}}-(1-\delta)+e m u_{b}\left(\mu v_{b}-\frac{1-\delta}{d}\right)\right] .} \\
\cdot\left[\left(\varepsilon+e m u_{b}\right) \mu v_{b}-\frac{r(1-\delta) u_{b} v_{b}}{1-u_{b}}-\left(\frac{\varepsilon}{d}-\varepsilon\right)(1-\delta)\right]+ \\
\frac{\varepsilon}{1-\delta+\mu v_{b}} \cdot\left[\varepsilon \mu v_{b}-\left(\frac{\varepsilon}{d}-\varepsilon\right)(1-\delta)\right]>0 .
\end{gathered}
$$

Therefore, the Routh - Hurwitz criterion is satisfied. Each parameter of the characteristic equation for $J\left(S_{a}\right)$ in M-3 is a special case of the parameter for $J\left(S_{b}\right)$ in M-5 when $\delta=0$ and $\mu=0$.

A proof of Corollary to Proposition 5. It is easy to see that the proofs of Propositions 5 (a) and 5 (b) remain in force without standard participation in profits, when $e=0$.

A proof of Proposition 6 (a) for R-1. The Routh - Hurwitz criterion is not violated:

$$
\begin{gathered}
a_{0}=-\left|J\left(S_{X}\right)\right|=\frac{\varepsilon c_{2} X}{q-1}>0, \\
a_{1}=-\frac{\varepsilon\left(c_{2} X+q\right)}{q-1}>0, \\
a_{2}=-\operatorname{Trace}\left[J\left(S_{X}\right]=\frac{c_{2} X}{q-1}+\varepsilon+\frac{\varepsilon}{d(q-1)}>0,\right. \\
a_{1} a_{2}-a_{0}=\frac{\varepsilon c_{2} X}{(q-1)^{2}}\left[c_{2} X+\varepsilon(q-1)+\frac{\varepsilon}{d}+1\right]+ \\
\frac{\varepsilon q}{(q-1)^{2}}\left[\varepsilon(q-1)+\frac{\varepsilon}{d}\right]>0 .
\end{gathered}
$$

Proofs of Proposition 5 (b) for M-5, Proposition 6 (b) for $R-1$ and Proposition 8 (b) for $R-2$ essentially repeat the proof of Proposition 2 (b) for M-3 and, therefore, are omitted.

A proof of Proposition 7 (a). For stationary state $E_{X}(61)$ in $\mathrm{X}-1$, (109) defines the Jacobi matrix:

$$
J\left(E_{X}\right)=\begin{array}{|c|c|}
\hline-d q<0 & c_{2}\left(1-u_{a}\right)>0 \\
\hline-k m X<0 & 0 \\
\hline
\end{array}
$$


The characteristic equation is

$$
\lambda^{2}+q d \lambda+c_{2} d X=0 .
$$

The stationary state $E_{X}$ is locally asymptotically stable since $\operatorname{Trace}\left[J\left(E_{X}\right)\right]=-d q<0,\left|J\left(E_{X}\right)\right|=c_{2} d X>0$.

This characteristic equation has two roots:

$$
\lambda_{1,2}=-\frac{q d}{2} \pm \sqrt{\frac{(q d)^{2}}{4}-c_{2} d X} .
$$

A proof of Proposition 7 (b). The roots of the characteristic equation are real and negative for a stable node if $c_{2} \leq c_{2}^{q}=$ $\frac{q^{2} d}{4 X}$ and complex conjugate with a negative real part for a stable focus if $c_{2}>c_{2}^{q}$. A period of fluctuations for a stable focus is about

$$
T_{X-1}=\frac{2 \pi}{\sqrt{c_{2} d X-\frac{(q d)}{4}^{2}}} .
$$

The higher is a magnitude of control parameter $c_{2}>c_{2}^{q}$, the shorter is the period of converging fluctuations in vicinity of the stationary state. On the other hand, the higher is a magnitude of control parameter $q$ the longer is the period of converging fluctuations.

An easy analytical proof of Proposition 8 (a) for $R-2$ is also skipped.

Proposition 9. Conclusions about the stability or instability of the stationary states examined in linearized systems should be extended to the original nonlinear systems in all cases except Proposition 4 for M-4.

A proof of Proposition 9 boils down to a lack of zero roots and purely imaginary roots of characteristic equations, allowing an application of Hartman - Grobman theorem to hyperbolic stationary states [18].

The numerical simulations use the general and specific parametric values. Stationary magnitudes (Table 7) and the roots of the characteristic equations (Table 8) support the above propositions.

Table 7. The stationary magnitudes in the alternative models

\begin{tabular}{|c|c|c|c|}
\hline Model & $\begin{array}{c}\text { Accumulation } \\
\text { rate }\end{array}$ & Employment ratio & Relative wage \\
\hline M-5 $(\delta=0.3)$ & 0.7 & 0.507 & $\begin{array}{c}0.827 \text { (gross). } \\
0.579 \text { (net) }\end{array}$ \\
\hline M-4 $(\delta=0.12)$ & 0.88 & 0.508 & $\begin{array}{c}0.862 \text { (gross). } \\
0.759 \text { (net) }\end{array}$ \\
\hline M-2, M-3 & 1 & 0.508 & 0.879 \\
\hline M-1 & 1 & 0.510 & 0.879 \\
\hline R-1, X-1, R-2 & 1 & 0.950 & 0.879 \\
\hline
\end{tabular}

Table 8. The roots of the characteristic equations and classification of the stationary states in the three-dimensional models

\begin{tabular}{|c|c|c|c|c|}
\hline Model & $\lambda_{1}$ & $\operatorname{Re}\left(\lambda_{2}, \lambda_{3}\right)$ & $\operatorname{Im}\left(\lambda_{2}, \lambda_{3}\right)$ & Stationary state \\
\hline M-3 & 26.82 & -0.125 & \pm 0.452 & Saddle-focus unstable \\
\hline M-5 & -67.33 & -0.115 & \pm 0.385 & Focus-node stable \\
\hline R-1 & -10.22 & -0.126 & \pm 0.106 & Focus-node stable \\
\hline
\end{tabular}

\section{REFERENCES}

[1] L. Fanti, P. Manfredi. A Goodwin-type growth cycle model with profit-sharing, Economic Notes, Vol. 27, 371-402, 1998.

[2] R.M. Goodwin. A growth cycle, in: C.H. Feinstein (ed.). Socialism, Capitalism and Economic Growth, Cambridge University Press, Cambridge, 54-58, 1972.

[3] A.W. Phillips. The relation between unemployment and the rate of change of money wage rates in the United Kingdom, 1861-1957, Economica, Vol. 25, 283-99, 1958.

[4] A.V. Ryzhenkov. Employment-centred stabilization policy propelling the economy to "escape velocity", The $31^{\text {st }}$ International Conference of the System Dynamics Society, System Dynamics Society, 2013, Online Available: http://www.systemdynamics.org/web.portal?P1170+0 http://www.systemdynamics.org/web.portal?S1170+0

[5] F. Lordon. Cycles et chaos dans un modèle hétérodoxe de croissance endogène, Revue économique, Vol. 46, No. 6, 1405-1432, 1995.

[6] A.V. Ryzhenkov. Supposing a control law of capital accumulation for the modern Italian economy, The $26^{\text {th }}$ International Conference of the System Dynamics Society, System Dynamics Society, 2008, Online Available: http://www.systemdynamics.org/conferences/2008/proceed/ papers/RYZHE475.pdf

http://www.systemdynamics.org/conferences/2008/proceed/s upp/475.pdf

[7] A.V. Ryzhenkov. The structural crisis of capital accumulation in the USA and its causa prima, The $28^{\text {th }}$ International System Dynamics Conference, System Dynamics Society, 2010, Online Available:

http://www.systemdynamics.org/conferences/2010/proceed/ papers/P1353.pdf

http://www.systemdynamics.org/conferences/2010/proceed/s upp/S1353.pdf

[8] A.V. Ryzhenkov. Insights into income policy for enhancing employment and stability of capital accumulation, The $30^{\text {th }}$ International Conference of the System Dynamics Society, System Dynamics Society, 2012, Online Available: http://www.systemdynamics.org/conferences/2012/proceed/ papers/P1460.pdf

http://www.systemdynamics.org/conferences/2012/proceed/s upp/S1460.pdf

[9] E. Wolfstetter. Fiscal policy and the classical growth cycle, Zeitschrift für Nationalökonomie (The Journal of Economics), Vol. 42, 375-393, 1982.

[10] H.Yoshida, T. Asada. Dynamic analysis of policy lag in a Keynes-Goodwin model: stability, instability, cycles and chaos, Journal of Economic Behavior and Organization, Vol. 62, 
441-469, 2007.

[11] P. Flaschel. The Macrodynamics of Capitalism. Elements for a Synthesis of Marx, Keynes and Schumpeter, Springer Verlag, Heidelberg, 2009.

[12] R. W.Spencer, W. P. Yohe. The 'crowding out' of private expenditures by fiscal policy actions, Federal Reserve Bank of St. Louis Review, Vol. 52, 12-24, 1970.

[13] A. W. Phillips. A simple model of employment, money and prices in a growing economy, Economica, Vol. 73, 360-370, 1961.

[14] M.W. Hirsch. Systems of differential equations that are competitive or cooperative. IV: structural stability in three-dimensional systems, SIAM Journal on Mathematical Analysis, Vol. 21, No. 5, 1225-1234, 1990.

[15] K. Polanyi. The Great Transformation: The Political and Economic Origins of Our Time, Beacon Press, Boston, 1971.

[16] A.V. Ryzhenkov. Win-lose, lose-lose and win-win stabilization policies for a growth cycle, The 32nd International Conference of the System Dynamics Society, System Dynamics Society, 2014, Online Available: http://www. systemdynam-

ics.org/conferences/2014/proceed/papers/P1458.pdf;http://w ww.systemdynamics.org/conferences/2014/proceed/supp/S14 58.pdf

[17] A.V. Ryzhenkov. Socially efficient stabilization policy preventing aggravation modes of capital accumulation, in: A.V. Alekseev and L.K. Kazantzeva (editors). Resource and Institutional Conditions for Forming Innovative Economy, IEIE SB RAS, Novosibirsk, 23-38, 2015 (in Russian).

[18] G. Gandolfo. Economic Dynamics. Fourth edition, Springer, Heidelberg, 2010.

[19] J.D. Sterman. Business Dynamics: Systems Thinking and Modeling for a Complex World, Irwin / McGraw-Hill, Boston a. o., 2000.

[20] G20 Policy Priorities on Labour Income Share and Inequalities, September 2015, Online Available:

https://g20.org/wp-content/uploads/2015/09/1-Annex-I-G20-P oli-

cy-Priorities-on-Labour-Income-Share-and-Inequalities-adopt ed.pdf

[21] O. Tudor. G20 almost rises to the challenge of the next global recession, 16 November 2015, Online Available: http://touchstoneblog.org.uk/2015/11/g20-almost-rises-to-the -challenge-of-the-next-global-recession/

[22] J. Cassidy. How Markets Fail. The Logic of Economic Calamities, Farrar, Straus and Giroux, New-York, 2009.
[23] A.V. Ryzhenkov. Unfolding the Eco-wave. Why Renewal is Pivotal, John Wiley \& Sons Ltd, Chichester a. o., 2000.

[24] K. Marx. The Grundrisse. Notebook VI. The Chapter on Capital (continuation), February 1858, Online Available: http://www.marxists.org/archive/marx/works/1857/grundriss e/ch11.htm\#p559

[25] Labour Markets, Institutions and Inequality: Building Just Societies in the 21st Century 24, ILO, February 2015. Online Available:

http://www.ilo.org/global/publications/books/WCMS_34662 9/lang--en/index.htm

[26] F. Jaumotte, C. O. Buitron. Inequality and labor market institutions, IMF, July 2015, Online Available: https://www.imf.org/external/pubs/ft/sdn/2015/sdn1514.pdf

[27] A.V. Ryzhenkov. Controlling employment, profitability and proved non-renewable reserves in a theoretical model of the U.S. Economy, The $25^{\text {th }}$ International Conference of the System Dynamics Society, System Dynamics Society, 2007, Online Available:

http://www.systemdynamics.org/conferences/2007/proceed/ papers/RYZHE406.pdf;

http://www.systemdynamics.org/conferences/2007/proceed/s upp/406.pdf

[28] J.T. Addison. The Economics of Codetermination. Lessons from the German Experience, Palgrave Macmillan, Ebook (PDF), 2009.

[29] A.V. Ryzhenkov. An enhancement for the textbook's models of natural resources and economic growth, The $33^{\text {rd }}$ International Conference of the System Dynamics Society, System Dynamics Society, 2015, Online Available: http://www.systemdynamics.org/conferences/2015/index.html

[30] G20 Leaders' Communiqué, Antalya Summit, Turkey, 15-16 November 2015, Online Available: http://europeansting.com/2015/11/16/g20-live-g20-leaders-c ommunique-antalya-summit-15-16-november-2015/

[31] A.V. Ryzhenkov. Scenarios of macroeconomic development of the USA in the $21^{\text {st }}$ century and unresolved issues in "neoclassical" modeling of ecological and economic macrosystem. A paper presented (in Russian) at "Globalistics-2015", the Moscow State University, the $3{ }^{\text {rd }}$ Plenary Session "Modeling and Forecasting of Global Development in the $21^{\text {st }}$ Century: Contours of New Architecture for Global Governance", Russia, Moscow, 27 October 2015, [The Program] Online Available:

http://www.skisd.org/wp/conference2/en/conference-progra $\mathrm{m} /$ program/ 